\title{
Analysis of a novel solar electricity generation system using cascade Rankine cycle and steam screw expander
}

\author{
Jing Li, Pengcheng Li, Gang Pei*, Jahan Zeb Alvi, Jie Ji \\ Department of Thermal Science and Energy Engineering, \\ University of Science and Technology of China, Jinzhai Road 96, Hefei City, \\ Anhui Province, People's Republic of China
}

\begin{abstract}
A novel solar electricity generation system (SEGS) using cascade cycle is proposed. The top and the bottom are steam Rankine cycle (SRC) and organic Rankine cycle (ORC). Particulary, screw expander (SE), which is characterized by good applicability in power conversion with steam-liquid mixture, is employed in the SRC. Steam is generated directly in the parabolic trough collectors (PTC) and expands in the SE. The heat released by steam condensation is used to drive the ORC. This type of SEGS has the advantages of avoidance of superheated steam, moderate operating temperature and pressure, low technical requirements in heat collection and storage, and suitableness for distributed power generation. Simulation of the system performance is conducted on the use of ten ORC fluids. Four hot/cold side temperatures of 473/313 K, 473/293 K, 523/313 K and 523/293 K are exemplified. The results indicate the ORC evaporation temperature corresponding to theoretical maximum solar power efficiency fails to provide a pressure ratio (PR) that matches the SE built-in PR. Off-design operation of the SE is recommended for the purpose of higher system efficiency and simpler ORC turbine. Efficiency of 13.68-15.62\% for the proposed system can be achieved.
\end{abstract}


Keywords: screw expander; solar electricity generation system; steam Rankine cycle; organic Rankine cycle; pressure ratio

*Corresponding author. Tel./Fax: +86 551 63607367. E-mail: peigang@ustc.edu.cn.

\section{Introduction}

Thermal electricity generation is one of the most important approaches to utilize solar energy. This industry is booming rapidly in recent years. The global operational solar electricity generation systems (SEGSs) in 2014 reached $4287 \mathrm{MW}$, and the systems under construction exceeded 2000 MW. Among the commerical SEGSs, parabolic trough collectors (PTC)-based systems are proven to be the most mature and predominant, which amount to approximately $90 \%$ of the total capacity of operational and under-construction plants [1].

PTC power plants with direct steam generation (DSG) are an alternative option for future cost reduction in SEGS. The DSG solar thermal power technology has been widely investigated [2-6]. In a DSG system, steam is directly generated in the solar field, hence avoiding the use of a boiler in the power section. The solar field recirculating pump consumption is also reduced. The collectors benefit from the constant temperature and high coefficient of heat transfer in the evaporation region of water. The feasibility of DSG technology in SEGS was manifested in the Direct Solar Steam (DISS) project funded by European Union, which had been operated for more than $6000 \mathrm{~h}$ [7]. DSG in the absorber tubes was deemed as a promising option to improve its competitiveness. Thermodynamic losses within oil-water/steam heat exchanger was obviated and hence higher steam temperature and higher SRC 
efficiency were attained. A $26 \%$ reduction in the levelized electricity cost seemed to be achievable [8]. A demonstration plant of 8 MWht was also built by Abengoa Solar [9]. The plant consisted of an evaporator field with three parallel loops and a superheater field with two loops in order to work at $8.5 \mathrm{MPa}$ and $723 \mathrm{~K}$. During one year operation, an innovative control strategy system that guaranteed the stability of the plant on transient conditions was validated. Different configurations of interconnections between collectors with ball joints and flexible rotation joints were evaluated. The first commercial PTC power plant with DSG technology in the world has been producing electricity since 2011 [10]. The 5 MWe solar thermal power plant located in Kanchanaburi /Thailand uses a new generation of PTC made of composite material combined with an efficient thin-glass mirror which reflects more than $95 \%$ of the sun radiation. After two years of successful operation, the power plant shows practical applicability of the DSG technology. The operation of the plant in sub-tropical climate characterized by frequent occurrence of cloudy phenomena, which sets high requirements on the transient control of PTC loops, has proven the reliability of the technology under nonideal condition for SEGSs.

Like most PTC-SEGSs with heat transfer fluid (HTF) of oil and molten salt, the aforementioned SEGSs with DSG generally use turbine- based steam Rankine cycle (SRC) for power conversion, which have some disadvantages as follows.

First, only superheated steam is allowed to enter the turbine to avoid condensation of vapour during the expansion process. If water droplets are formed, they may impinge on the blades of turbine at high speed, and cause damage and reduce 
mechanical efficiency. The SEGS developed in the DISS project had steam temperature of $673 \mathrm{~K}$ and pressure of $10 \mathrm{MPa}$ at the turbine inlet $[10,11]$. There was a degree of superheat of about $90 \mathrm{~K}$. The plant developed in INDITEP project (the logical continuation of the DISS project) had steam temperature of $673 \mathrm{~K}$ and pressure of $6.5 \mathrm{MPa}$ at the turbine inlet [12]. The degree of superheat was about $119 \mathrm{~K}$. The need of superheat significantly increases the turbine inlet temperature, while the increment in the SRC efficiency is limited. The detail will be provided in Section 5.1.

Second, the technical requirements in solar energy collection are high in order to achieve the high temperature heat source for the SRC. The glass-to-metal sealing of the PTC receiver is a type of tubular sealing, which involves not only appropriate mechanical strength but also excellent gas tightness on high vacuum conditions. Owing to the thoroughly different characteristics of metal and glass (e.g. thermal expansion coefficient and wettability), sealing failure/degradation of the receiver may be caused when the operating temperature fluctuates from about $673 \mathrm{~K}$ at daytime to $300 \mathrm{~K}$ at night. This failure/degradation proved to be a big problem in the early SEGSs [13]. To reach a temperature of $673 \mathrm{~K}$, the geometric concentration ratio of PTC is generally more than 60 [14]. Large concentration ratio leads to high accurate tracking system, frequent maintenance, repair/replacement of moving parts and gears.

Third, it is difficult to store high grade heat. Thermal storage is vital to maintain the continuity of solar thermal power generation. HTF with mineral oil was used in USA SEGS I for $3 \mathrm{~h}$ heat storage. In the temperature range below $573 \mathrm{~K}$, this technology was successful for helping the plant dispatch the generated electricity to 
meet the utility peak loads in the non-sunlight periods. But for later, more efficient SEGS that operated at higher solar field temperature, the mineral oil became very flammable and could not be used any more. Molten salt has been adopted as HTF in the USA Solar-Two power tower project. Due to its simple storage concept it is also suggested for use in PTC power plants [15]. Recently the world's largest solar thermal plant with molten salt storage system has come online in Arizona [16]. However, the low thermal conductivity and high melting point (which causes the freezing problem) of the salt are two obstacles which must be overcome before making full use of this storage technology.

Fourth, the plants have to be large to be economic. The capital cost per kWe of a SEGS generally decreases with the increment in installed capacity [17]. The reason is some fixed costs for a larger plant are approximately the same as those for a smaller plant, and the devices e.g. turbine, pump and generator are more efficient at higher power. Usual capacity of PTC-SEGS ranges from a few to tens of MW, some even reach two or three hundred MW. Millions of square meters of flat land is necessary, which can only be met in the Gobi desert or sparsely populated areas.

The above problems can be solved or eased by the usage of screw expander (SE) [18] and reciprocating expander [19, 20]. Particularly, SE is a kind of volumetric expander which uses a rotary type positive displacement mechanism in the absence of high speed fluid. In general, it consists of a pair of helical screws and a shell casing. Fluid moves from the groove of relative small volume at the inlet towards other grooves of large volume, and drives the twin helical screws in opposite directions. 
During the process, pressure and temperature of the fluid decrease, and power is delivered by the shaft. Compared with turbine, SE is capable to handle steam-liquid mixture as well as saturated steam and liquid. It has characteristics of quick start-up and shut-down, high tolerance for the heat source fluctuation in pressure and volumetric flow, low rotation speed, simpler structure, low maintenance cost, easy assembly and excellent mobility. These advantages make SE suitable for low-medium temperature DSG applications.

SE technology has reached a considerable degree of maturity. There are many SE products on the worldwide market. For example, the SEs produced by Jiangxi Huadian Electrical Power Co.,Ltd. have been successfully applied in electric power, iron and steel, petrochemical, metallurgy, printing and dyeing, building materials, paper and other industries [21]. Heliex Power's SEs became commercially available in 2013 following several years of research and development at its dedicated manufacturing and test facility in East Kilbride, Scotland. With a global network of distributors, these SEs have been installed at a number of European sites including UK, France and Italy [22]. Opcon's SEs have been used to produce profitable emission-free electricity from saturated or superheated steam. They can work at pressure up to $3.5 \mathrm{MPa}$ and can be ordered in a number of sizes ranging from 150 to $1600 \mathrm{~kW}$. Applications include large process-industry plants, power stations or onboard large ships [23]. Some SE-based power plants in operation are presented in Table 1. It seems that $\mathrm{SE}$ is more competitive than turbine when the heat source temperature is below $573 \mathrm{~K}$ and the power capacity is smaller than $2.0 \mathrm{MW}$. 
Though currently the SE-based SRC is mainly employed for geothermal power generation and waste heat recovery, it is promising in SEGS application regarding the elimination of superheater. Solar energy collection can thus be performed at temperature below $573 \mathrm{~K}$, while the power efficiency remains comparable with that of mainstream turbine-based SEGS.

One challenge with the SE-based SEGS is the low design pressure ratio (PR) of expander for the sake of cost-effectiveness. According to the existing plants, common design $\mathrm{PR}$ of $\mathrm{SE}$ is about 2.5 to 8 . It means that given the saturation steam temperature of $523 \mathrm{~K}$ (with a saturation pressure of $3.98 \mathrm{MPa}$ ), the design condensation temperature shall be higher than $424 \mathrm{~K}$ (with a saturation pressure of 0.49 MPa). The avaible energy of high temperature steam can not be fully extracted through a single SE. One solution is to assemble two or more SEs in series. But it makes the design more difficult (especially the coincidence of axes). The feasibility of SEs in series has not been demonstrated yet.

To produce electricity on the condition of large temperature difference between the hot and cold sides, cascade steam-organic Rankine cycle (SORC) will be more beneficial than single stage SRC. Organic Rankine cycle (ORC) displays a number of advantages over SRC at low-medium temperature. The ORC fluid of low boiling point shows good reaction to the fluctuation in ambient temperature and enables efficient use of low-temperature heat sources. The relatively lower latent heat of organic fluid makes the design and manufacture of low power expander easier. With the ORC bottoming cycle, the SE in the SRC can be also designed at smaller size. 
Meanwhile, the SORC offers higher power efficiency compared with solo SRC [24-26].

In this work, a solar thermal power generation system using cascade Rankine cycle is proposed. To the best knowledge of the authors, it is the first time that screw expander-based SRC has been combined with ORC for solar thermal power system application. Steam is generated directly in the solar fields. The system differs from conventional SEGS with DSG regarding the employment of cascade Rankine cycle and screw expander. Special design is conducted to guarantee the stability of power generation. Thermodynamic performance of the system is analyzed on the use of 10 dry ORC fluids. The fluid evaporation temperature is optimized with respect to the heat-to-power conversion efficiency and the expander pressure/volume ratio.

\section{Thermal storage for the DSG solar thermal power generation system}

Numbers of materials such as thermal oil, molten salt, water and phase change materials (PCM) are alternatives for heat storage in the DSG system. Sensible heat storages of thermal oil and molten salt have been employed in commercial SEGS with demonstrated technical feasiblity, and they can be also applied in the DSG system. Notably, water and PCM have not been commonly used in SEGS yet, but they may peculiarly suit the DSG system.

Water accumulator as denoted by the dash rectangle in Fig. 1 is an attractive option for compensation of fast transients in insolation and can meet the requirements for buffer storage in DSG solar power systems [27]. The major problem of using water for heat storage in conventional DSG systems is the expensive pressure vessel 
that may work up to $12 \mathrm{MPa}$. However, it won't be so crucial in the proposed system because of the much lower operating temperature and pressure in PTC. Pressure from 1.0 to $3.0 \mathrm{MPa}$ and temperature from $473 \mathrm{~K}$ to $573 \mathrm{~K}$ are sufficient for SE power conversion. In fact, the temperature and pressure may be even lower than those of thermal oil in current commercial SEGSs. For example, the mixture of two aromatic hydrocarbons (diphenyl and diphenyl ether, THERMINOL® VP-1) is favorite fluid to transport and store heat from the solar field. The saturation pressure of THERMINOL® VP-1 at $673 \mathrm{~K}$ is about $1.2 \mathrm{MPa}$. The design pressure at the solar field inlet has been set at $2.5 \mathrm{MPa}$ to avoid evaporation at the field outlet [6]. The technical issues associated with THERMINOL ${ }^{\circledR}$ VP-1 in the receiver, storage tank, etc. are similar with those in the DSG system. Since the thermal oil technology has been widely accepted, water storage technology of modest pressure and temperature shall be feasible.

Phase change material (PCM) is another choice for the thermal storage, which can store much heat per unit volume. Lots of PCMs are available based on the type of application. For melting ranges between $373 \mathrm{~K}$ and $473 \mathrm{~K}$, salt hydrates and sugar alcohols may be used. For higher melting temperatures, salts and their mixtures e.g. $\left(\mathrm{KNO}_{3}+\mathrm{NaNO}_{3}\right)$ are applicable. The main defect of previous turbine-based DSG solar thermal power plants is the complex solar field control under fluctuating solar radiation. It is difficult to maintain constant temperature and pressure at the outle of the solar field. Fortunately, superheat of water prior to expansion becomes unnecessary when SE is used. By integrating with a PCM unit, the SE can operate at 
steady conditions and water leaving the solar field can be at either subcooled, saturated, or superheated state.

\section{System description}

The schematic diagram of the SEGS with cascade cycle is depicted in Fig.1. In this work, the system using PCM is excemplified. Cycle I (red colour) and Cycle II (blue colour) are the SRC and ORC subsystems. Cycle I mainly consists of SE, condenser (HX1), pumps (P1, P3), heat storage unit with PCM, and collectors. Cycle II is comprised of expander, condenser (HX2), pump (P2). HX1 serves as the evaporator for Cycle II. Either volumetric or turbo expander can be used in the ORC. However, turbo expander is more favorable for the bottom cycle, which is to be discussed in Section 5.3.

There can be three operating modes for the system:

I ) The system needs to generate electricity and solar radiation is abundant. In this mode, V1, V2, V3 are open and P1 runs. Both SRC and ORC operate. Water is heated and vaporized in PTC. The saturated steam flows into the SE, exporting power during the process of enthalpy drop. The outlet vapor is condensed to saturated liquid in HX1, pressurized by $\mathrm{P} 1$ and then is sent back to the PTC. The condensation heat is used to vaporize the organic fluid in the ORC. If irradiation is too strong, V4 can be open and P3 can run to prevent water from being superheated in the PTC, and part of the solar energy is stored in the PCM.

II ) The system does not need to generate electricity but irradiation is strong. V2, V3, V4 are open and P3 runs. Solar heat is transferred to the PCM by water. 
III) The system needs to generate electricity but irradiation is weak or unavailable. V1, V2, V5 are open and P1 runs. Both SRC and ORC operate. Heat is released by the PCM and converted into power.

The proposed system is advantageous compared with commercial PTC-SRC SEGSs. It has comparable power efficiency, while the temperature and pressure in the solar field are much lower. The technical requirements in solar energy collection and heat storage are thus reduced. Unlike steam turbine which is favorably adopted in large scale SEGS, SE is capable to convert heat to power efficiently with capacity below 1.0 MW and rotation speed below 3600 RPM. This enables distributed power generation. Heat and power can be supplied to consumers near the point of usage, making the system more cost-effective. Moreover, the cascade system can work efficiently at low ambient temperature. For a conventional SRC, it is difficult to realize efficient expansion of steam at condensation temperature below $306 \mathrm{~K}$ owing to the low pressure. The technical limit for maintaining a vacuum below $5 \mathrm{kPa}$ in the steam condenser has been pointed out in previous works [28-30]. This problem is more critical as the PTC-SRC system scales down. While the PTC-SORC system can react to low ambient temperature owing to the much higher saturation pressure of ORC fluid.

The PTC-SORC system also has advantages over PTC-ORC system. Most ORC fluids will suffer from thermal instability, flammability or low thermodynamic performance in the temperature range from $473 \mathrm{~K}$ to $573 \mathrm{~K}$. Contrastly, water is of non-fouling, non-corrosiveness, non-toxicity and non-flammability, and has good 
attainability. Besides, in the absence of superheater, SRC can offer a higher power efficiency than ORC. An efficiency comparsion is made in Table 2. The dash lines indicate the cases that evaporation temperature exceeds the critical temperature of the fluid, which are not taken into account. Water possess higher thermal power conversion efficiency than the organic fluids when the expander inlet is at saturated state, and this superiority is more appreciable as the evaporation temperature rises.

\section{Mathematical models}

\subsection{Collectors}

A type of PTC installed in the USA with up to $2700 \mathrm{~m}^{2}$ of aperture area is referenced here [31]. The performance formula of a single PTC provided by the manufacturer is [32]:

$$
\eta_{P T C}(T)=0.762-0.2125 \times \frac{T-T_{a}}{G_{b}}-0.001672 \times \frac{\left(T-T_{a}\right)^{2}}{G_{b}}
$$

where $G_{b}$ is beam solar radiation $\left(\mathrm{W} / \mathrm{m}^{2}\right) ; T$ is collector inlet temperature $(\mathrm{K})$.

Hundreds of collectors are usually required in SEGS, the temperature difference between neighboring collectors is supposed to be small. To calculate the overall collection efficiency, it is reasonable to assume that the average operating temperature of the collector changes continuously from one module to another.

Water in PTC experiences liquid phase and binary phase, and finally becomes saturated vapor. Collector efficiency in binary phase region can be calculated with Eq. (1) as the temperature remains constant. For liquid phase region, in order to reach an outlet temperature $T_{\text {out }}$ with an inlet temperature $T_{\text {in }}$, the required collector area is obtained by 


$$
A_{l}=\int_{T_{\text {in }}}^{T_{\text {out }}} \frac{m_{\mathrm{I}} \cdot C_{p}(T)}{\eta_{P T C}(T) \cdot G_{b}} d T
$$

where $m_{\mathrm{I}}$ is mass flow rate of water in Cycle I .

Heat capacity of water can be expressed by a first order approximation:

$$
C_{p}(T)=C_{p, 0}+\alpha\left(T-T_{0}\right)
$$

Where $C_{p, 0}$ is heat capacity corresponding to reference temperature $T_{0}$.

With $c_{1}=0.2125 / G_{b}, \quad c_{2}=0.001672 / G_{b}$, the collector area according to Eqs. (1) -

(3) is calculated by

$$
A_{l}=\frac{m_{\mathrm{I}}}{c_{2} G_{b}\left(\theta_{2}-\theta_{1}\right)}\left[\left(C_{p, a}+\alpha \theta_{1}\right) \ln \frac{\left(T_{\text {out }}-T_{a}-\theta_{1}\right)}{T_{\text {in }}-T_{a}-\theta_{1}}+\left(C_{p, a}+\alpha \theta_{2}\right) \ln \frac{\theta_{2}-T_{\text {in }}+T_{a}}{\theta_{2}-T_{\text {out }}+T_{a}}\right]
$$

where $\theta_{1}$ and $\theta_{2}$ are the arithmetical solutions of Eq. (5) $\left(\theta_{1}<0, \theta_{2}>0\right)$.

$$
\begin{gathered}
0.762-c_{1} \theta-c_{2} \theta^{2}=0 \\
C_{p, a}=C_{p, 0}+\alpha\left(T_{a}-T_{0}\right)
\end{gathered}
$$

Collector efficiency in liquid phase region is calculated by

$$
\eta_{P T C, l}=\frac{m_{\mathrm{I}} \Delta h_{l}}{G_{b} A_{l}}
$$

Overall collector efficiency is calculated by Eq. (8)

$$
\eta_{P T C}=\frac{Q}{G_{b}\left(A_{l}+A_{b}\right)}=\frac{\Delta h_{l}+\Delta h_{b}}{\frac{\Delta h_{l}}{\eta_{P T C, l}}+\frac{\Delta h_{b}}{\eta_{P T C, b}}}
$$

where $\Delta h_{l}$ and $\Delta h_{b}$ are the enthalpy increments of water in liquid phase and binary phase regions.

\subsection{Expanders}

$T-S$ diagram of an ideal cascade SRC system is shown in Fig. 2. To clearly illustrate the thermodynamic process, the pump outlet state points 4 and 8 are exaggerated. The 
ideal system will be referred in Section 5.2 to illustrate its efficiency superiority over single stage SRC. T-s diagram of a practical SORC can be depicted in Fig.3. The work generated by SE and turbine is defined as Eq. (9) and (10):

$$
\begin{gathered}
W_{S E}=m_{\mathrm{I}}\left(h_{1}-h_{2}\right)=m_{\mathrm{I}}\left(h_{1}-h_{2 s}\right) \varepsilon_{S E} \\
W_{T}=m_{\mathrm{II}}\left(h_{5}-h_{6}\right)=m_{\mathrm{II}}\left(h_{5}-h_{6 s}\right) \varepsilon_{T}
\end{gathered}
$$

The volume ratio (VR) for each expander is defined as

$$
V R=\frac{v_{\text {out }}}{v_{\text {in }}}
$$

The PR is defined as

$$
P R=\frac{P_{\text {in }}}{P_{\text {out }}}
$$

\subsection{Heat exchanger}

Heat balance in $\mathrm{HX} 1$ is expressed by

$$
m_{\mathrm{I}}\left(h_{2}-h_{3}\right)=m_{\mathrm{II}}\left(h_{5}-h_{8}\right)
$$

\subsection{Pumps}

The work required by pumps is expressed by

$$
\begin{gathered}
W_{p 1}=m_{\mathrm{I}}\left(h_{4}-h_{3}\right)=m_{\mathrm{I}}\left(h_{4 s}-h_{3}\right) / \varepsilon_{p} \\
W_{p 2}=m_{\mathrm{II}}\left(h_{8}-h_{7}\right)=m_{\mathrm{II}}\left(h_{8 s}-h_{7}\right) / \varepsilon_{p}
\end{gathered}
$$

\subsection{Thermal efficiency}

Thermal efficiency $\left(\eta_{T}\right)$ of the proposed system indicates how effectively solar radiation is converted into electricity.

$$
\eta_{T}=\eta_{S O R \dot{C}} \eta_{P T C}=\frac{W_{n e t}}{G_{b} \cdot A}
$$

where 


$$
\begin{gathered}
\eta_{S O R C}=\frac{W_{\text {net }}}{m_{\mathrm{I}}\left(h_{1}-h_{4}\right)} \\
W_{n e t}=\left(W_{S E}+W_{T}\right) \cdot \varepsilon_{g}-\left(W_{p 1}+W_{p 2}\right)
\end{gathered}
$$

Analogously, for the SRC and ORC,

$$
\begin{gathered}
\eta_{S R C}=\frac{W_{S E} \cdot \varepsilon_{g}-W_{p 1}}{m_{\mathrm{I}}\left(h_{1}-h_{4}\right)} \\
\eta_{O R C}=\frac{W_{T} \cdot \varepsilon_{g}-W_{p 2}}{m_{\mathrm{II}}\left(h_{5}-h_{8}\right)}
\end{gathered}
$$

\subsection{Exergetic efficiency}

The exergetic efficiency of the PTC-SORC system is the ratio of the net power output to the exergy released by solar radiation,

$$
\eta_{e x}=\frac{W_{n e t}}{E_{S}}
$$

$E_{S}$ is calculated by [33]

$$
E_{s}=G_{b} A\left[1-\frac{4 T_{a}}{3 T_{s}}(1-0.28 \ln f)\right]
$$

where $f$ is the dilution factor, $f=1.3 \times 10^{-5}$

The exergy losses in the components are estimated by the equations in Table 3. The ambient temperature is deemed as the reference temperature.

\section{Results and discussion}

5.1. The influence of superheat on the SRC efficiency

Based on Eq.(19), the SRC efficiency variation with expander inlet temperature is shown in Fig.4. The expander inlet pressure is 2.0, 2.5, 3.0 and 6.5 MPa. The corresponding saturation temperature of water is 485.6, 497.1, 507 and $554 \mathrm{~K}$, respectively. Efficiencies of the expander, pump and generator are $0.75,0.80$, and 
0.95. The condensation temperature is $313 \mathrm{~K}$. The dark yellow dot line with stars represents the exhaust quality of 0.9 at the expander outlet. Point A has the same expander inlet temperature and pressure as those of the INDITEP plant [12]. To gurantee $90 \%$ dryness of the exhaust, the degree of superheat at the expander inlet is generally higher than $100 \mathrm{~K}$, and it increases with the increment in the inlet pressure. A high degree of superheat only raises SRC efficiency by less than 3\%. Regarding the lower collector efficiency at higher temperature, the overall solar thermal power efficiency may even decrease. In fossil fuel-fired SRC plants using turbine as the expander, reheat is favorably employed to elevate the quality at LP turbine outlet at given HP turbine inlet temperature. However, in solar thermal power systems it will be difficult to implement a reheat cycle due to the fluctuation of heat source. SE offers an alternative solution. Since the SRC efficiency is improved slightly by the degree of superheat, saturated steam at SE inlet is assumed in the following discussion.

\subsection{Efficiency superiority of cascade Rankine cycle}

At present, demonstration of efficiency superiority of cascade Rankine cycle without superheat at the expander inlet is lacked. This section argues about the superiority on the thermodynamic basis. For a simpler demonstration, water is taken for the bottom cycle. The cascade SRC has $T-s$ diagram as presented in Fig. 2. The relationship between efficiencies of the cascade and single-stage SRC system is deduced as follows.

$$
\begin{gathered}
\because \quad \eta_{\text {cas }}=\frac{m_{\mathrm{I}}\left(h_{1}-h_{2}\right)+m_{\mathrm{II}}\left(h_{2}-h_{6}\right)-m_{\mathrm{I}}\left(h_{4}-h_{3}\right)-m_{\mathrm{II}}\left(h_{8}-h_{7}\right)}{m_{\mathrm{I}}\left(h_{1}-h_{4}\right)} \\
m_{\mathrm{I}}\left(h_{2}-h_{3}\right)=m_{\mathrm{II}}\left(h_{2}-h_{8}\right)
\end{gathered}
$$




$$
\begin{aligned}
& \eta_{\text {single }} \approx \frac{h_{1}-h_{6}+h_{3}-h_{4}-h_{8}+h_{7}}{h_{1}-h_{4}+h_{3}-h_{8}} \\
& \therefore \quad \eta_{\text {cas }}=1+\frac{\left(h_{2}-h_{3}\right)\left(h_{7}-h_{6}\right)}{\left(h_{1}-h_{4}\right)\left(h_{2}-h_{8}\right)} \\
& \eta_{\text {single }} \approx 1+\frac{h_{7}-h_{6}}{h_{1}-h_{4}+h_{3}-h_{8}} \\
& \because \quad h_{1}-h_{2}+h_{3}-h_{4}>0 \\
& \therefore \quad\left(h_{3}-h_{8}\right)\left(h_{1}-h_{2}+h_{3}-h_{4}\right)>0 \\
& \therefore \quad h_{1} h_{3}-h_{1} h_{8}+h_{2} h_{8}-h_{2} h_{3}+h_{3}^{2}-h_{3} h_{8}-h_{3} h_{4}+h_{4} h_{8}>0 \\
& \therefore \quad\left(h_{2}-h_{3}\right)\left(h_{1}-h_{4}+h_{3}-h_{8}\right)<\left(h_{1}-h_{4}\right)\left(h_{2}-h_{8}\right) \\
& \because \quad h_{6}-h_{7}>0 \\
& \therefore \quad \frac{h_{7}-h_{6}}{h_{1}-h_{4}+h_{3}-h_{8}}<\frac{\left(h_{2}-h_{3}\right)\left(h_{7}-h_{6}\right)}{\left(h_{1}-h_{4}\right)\left(h_{2}-h_{8}\right)} \\
& \therefore \quad 1+\frac{h_{7}-h_{6}}{h_{1}-h_{4}+h_{3}-h_{8}}<1+\frac{\left(h_{2}-h_{3}\right)\left(h_{7}-h_{6}\right)}{\left(h_{1}-h_{4}\right)\left(h_{2}-h_{8}\right)} \\
& \therefore \quad \eta_{\text {single }}<\eta_{\text {cas }}
\end{aligned}
$$

Therefore, a cascade Rankine cycle has great potential to be more efficient than single stage Rankine cycle. The above theoretical deduction is based on water, but the result is expected to be valid for organic fluids. A cascade cycle offers a higher temperature in the heating process (from about $T_{3}$ to $T_{1}$ ) than a single stage one (from about $\mathrm{T}_{7}$ to $\mathrm{T}_{1}$ ), which is beneficial to the heat-to-power conversion efficinecy. In practice, a higher evaporation temperature of working fluid in the bottom cycle offers a higher average temperature of water in the heat transfer process from the outside, but is accompanied by a larger exergy destruction in the internal heat exchanger (i.e., the evaporator in the bottom cycle). The optimal evaporation temperature of the bottom working fluid is a compromise between the two factors.

\subsection{Energetic efficiency variation}


Ten typical organic fluids are selected for the bottom Rankine cycle. Their thermodynamic and environmental properties are summarized in Table 4. Saturation pressures of the fluids at $293 \mathrm{~K}$ are higher than $5 \mathrm{kPa}$. Four cases of the hot /cold side temperatures are exemplified, i.e. $T_{H}=473 \mathrm{~K}$ and $T_{L}=313 \mathrm{~K}, T_{H}=473 \mathrm{~K}$ and $T_{L}=293$ $\mathrm{K}, \mathrm{T}_{\mathrm{H}}=523 \mathrm{~K}$ and $\mathrm{T}_{\mathrm{L}}=313 \mathrm{~K}, \mathrm{~T}_{\mathrm{H}}=523 \mathrm{~K}$ and $\mathrm{T}_{\mathrm{L}}=293 \mathrm{~K} . \mathrm{T}_{\mathrm{H}}$ is equal to the evaporation temperature of water in the $\mathrm{SRC}\left(\mathrm{T}_{1}\right) . \mathrm{T}_{\mathrm{L}}$ is equal to the condensation temperature of the $\mathrm{ORC}\left(\mathrm{T}_{7}\right)$, which is $10 \mathrm{~K}$ higher than the corresponding ambient temperature. Fixed parameters in calculation are given in Table 5.

Fig. 5 shows the variations of $\eta_{S R C}$ and $\eta_{O R C}$ with the ORC evaporation temperature $\left(\mathrm{T}_{5}\right)$ when $\mathrm{T}_{\mathrm{H}}=473 \mathrm{~K}$ and $\mathrm{T}_{\mathrm{L}}=313 \mathrm{~K} . \eta_{S R C}$ decreases almost linearly with the increment in $\mathrm{T}_{5}$, while $\eta_{O R C}$ climbs. At a given $\mathrm{T}_{5}$, fluid of higher critical temperature offers higher ORC efficiency. The efficiency difference between any two of the fluids gets larger as $\mathrm{T}_{5}$ increases. With $\mathrm{T}_{5}=390 \mathrm{~K}$, the $\mathrm{ORC}$ efficiencies are close to the SRC efficiency, and the highest one is about $12.24 \%$ for benzene while the lowest one is about $10.07 \%$ for R236ea.

Fig. 6 shows the cascade cycle efficiency varying with the ORC evaporation temperature. For each fluid, the efficiency is strongly correlated with $\mathrm{T}_{5}$, and the curve opens downward. The SORC can have a higher efficiency than single stage SRC, which can be deemed as the case that the ORC evaporation temperature is equal to the condensation temperature.

Fig. 7 shows the solar thermal power efficiency of the whole system $\left(\eta_{T}\right)$ varying with $\mathrm{T}_{5}$. The variations are similar for the ten fluids. For each fluid, $\eta_{T}$ first increases 
and then decreases with the increment in $\mathrm{T}_{5}$. Benzene and R236ea present the highest and lowest $\eta_{T}$, respectively. The intersections of the black solid line and the efficiency curves denote the peak efficiencies of the fluids $\left(\eta_{T, p}\right)$. In addition, with $\mathrm{T}_{\mathrm{H}}$ $=473 \mathrm{~K}, \eta_{P T C}$ varies slightly with $\mathrm{T}_{5}$, which is about $65.87-66.95 \%$ when $\mathrm{T}_{5}$ changes from $318 \mathrm{~K}$ to $418 \mathrm{~K}$.

Notably, $\eta_{T, p}$ is the theoretic maximum system efficiency with the assumption of constant expander efficiency. Given the hot/cold side temperatures and working fluid, $\mathrm{T}_{5, \mathrm{p}}$ might be not the optimum operating $\mathrm{ORC}$ evaporation temperature regarding the expander characteristics. The built-in VR and operating PR are two important parameters of SE. The former describes the ratio of the maximum swept volume of fluid in the expander immediately before the discharge port is exposed, to the volume of fluid contained in the inlet port. Given the size of SE and rotation speed, a low built-in VR is generally desirable because it maximizes the induced mass flow of fluid before the high pressure port is cut off. The greater the flow rate, the less appreciable the leakage loss. Reducing the built-in VR conduces to simpler and cheaper machine. But a too low built-in VR results in under-expansion of the working fluid and hence expulsion of the fluid at a high pressure. Available work is lost and the isentropic efficiency of the expander falls. There is a tradeoff between a lower built-in VR with lower cost and leakage losses, and a higher one with little under-/over-expansion loss. In practice, a built-in VR from 2.5 to 5.5 is favorable [34-37]. VR is a primary parameter in SE design, while PR influences its thermodynamic performance in operation. There is a maximum value of the overall isentropic efficiency as PR varies, 
which occurs when PR is approximately equal to the built-in PR. The operating PR may deviate from the built-in due to thermodynamic irreversibility or improper inlet pressure supplied. The ill-matching of these pressure ratios may lead to undesirable effects in the expander such as the "blowdown" or the "blowback" phenomenon and hence a loss of work [38]. The influence of PR on SE efficiency becomes less significant with the increment in the built-in VR, which is attributed to the lower loss of work at blowdown. Some experimental results of the off-design behavior of SE are shown in Fig. 8. For a SE with built-in VR $\left(\mathrm{r}_{\mathrm{v}}\right)$ of 5, the drop of isentropic efficiency from the maximum is only $10 \%$ when the operating PR increases by threefold as the built-in. SE is characterized by good part-load behavior in comparison with turbine and other positive displacement machines [39].

Fig. 9 shows the variations of operating VR for SRC and ORC, and PR for SRC with $\mathrm{T}_{5} . \mathrm{VR}$ and PR for SRC decrease with the increment in $\mathrm{T}_{5}$, and VR is lower than $\mathrm{PR}$. The VR is higher than 10 when $\mathrm{T}_{5}$ is lower than $373 \mathrm{~K}$. It indicates if the design $\mathrm{T}_{5}$ is determined by $\mathrm{T}_{5, \mathrm{p}}$ as shown in Fig. 7 , then the $\mathrm{SE}$ built-in VR will greatly exceed the commonly acceptable values. The SE may be excessively complicated and expensive.

For a SE with built-in VR of 5 , to enable a best expansion process, $\mathrm{T}_{5}$ shall be around $397 \mathrm{~K}$. This is a temperature matching the SE characteristics $\left(\mathrm{T}_{5, \mathrm{ch}}\right) . \mathrm{T}_{5 \text {,ch }}$ is higher than $\mathrm{T}_{5, \mathrm{p}}$, and $\eta_{T, c h}$ differs from $\eta_{T, p}$.

An ORC evaporation temperature of $\mathrm{T}_{5, \text { ch }}$ can minimize the thermodynamic irreversibility in the SE. However, $\eta_{T, c h}$ is lower than $\eta_{T, p}$ for each fluid, which 
indicates the thermodynamic irreversibility in other elements of the SORC system at $\mathrm{T}_{5, \mathrm{ch}}$ is larger than that at $\mathrm{T}_{5, \mathrm{p}}$. In practical operation, to maximize the system efficiency the optimum ORC evaporation temperature $\left(\mathrm{T}_{5, \mathrm{op}}\right)$ shall fullfill the inequation $\mathrm{T}_{5, \mathrm{p}} \leq \mathrm{T}_{5, \mathrm{op}} \leq \mathrm{T}_{5, \mathrm{ch}}$, which is also attributed to the SE characteristics. $\mathrm{T}_{5, \mathrm{op}}$ is the compromise between the irreversibilities in the SE and other elements of the SORC. It leads to a slightly lower SE efficiency than the design but better thermodynamic performance of the whole system [40]. Moreover, the system efficiency $\eta_{T, o p}$ at $\mathrm{T}_{5, \mathrm{op}}$ fullfills the inequation $\eta_{T, c h} \leq \eta_{T, o p} \leq \eta_{T, p}$.

Fig. 10 shows the variations of $\eta_{S R C}$ and $\eta_{O R C}$ with $\mathrm{T}_{5}$ when $\mathrm{T}_{\mathrm{H}}=473 \mathrm{~K}$ and $\mathrm{T}_{\mathrm{L}}$ $=293 \mathrm{~K}$. The variation of $\eta_{S R C}$ is the same as that in Fig. 5, but $\eta_{O R C}$ is higher at a given $T_{5}$ due to the lower temperature of heat sink.

The solar power efficiency varying with $\mathrm{T}_{5}$ is shown in Fig. 11. The system efficiency of each fluid corresponding to the best SE behavior is denoted by the dashed red line. Similarly with Fig. 7, Benzene and R236ea present the highest and lowest efficiency, respectively. As $\mathrm{T}_{\mathrm{L}}$ decreases, $\mathrm{T}_{5, \mathrm{p}}$ decreases but $\eta_{T, p}$ increases.

The variations of VR for the ORC are displayed in Fig. 12. Because the variations of VR and PR for the SRC are independent on $\mathrm{T}_{\mathrm{L}}$, they are not presented anymore. With a lower $\mathrm{T}_{\mathrm{L}}, \mathrm{VR}$ of each fluid for the ORC becomes larger at a given $\mathrm{T}_{5}$, which may lead to difficulty in the expander design for the ORC. Compared with volumetric expander, turbine is able to handle higher VR and seems more suitable for the application in the bottom cycle. Lower VR is also favorable for turbine to avoid multistage expansion [41]. Efficiency over $80 \%$ can be achieved for single-stage axial 
turbine only when the VR is below $50[42,43]$. Thankfully, VRs for the ORC at $\mathrm{T}_{5, \mathrm{ch}}$ are lower than 50 . Since $\mathrm{T}_{5, \mathrm{op}}$ is lower than $\mathrm{T}_{5, \mathrm{ch}}$, VRs can be further reduced.

Fig. 13 shows the variations of $\eta_{S R C}$ and $\eta_{O R C}$ with $\mathrm{T}_{5}$ when $\mathrm{T}_{\mathrm{H}}=523 \mathrm{~K}$ and $\mathrm{T}_{\mathrm{L}}$ $=313 \mathrm{~K}$. Because only subcritical ORC is considered in this work, efficiencies of some fluids are missing when $\mathrm{T}_{5}$ is higher than their critical temperatures. With a higher $\mathrm{T}_{\mathrm{H}}$, the $\mathrm{SRC}$ efficiency at a given $\mathrm{T}_{5}$ is increased.

Variations of $\eta_{T}$ are shown in Fig. 14. The collector efficiency is $60.79-62.88 \%$ when $\mathrm{T}_{5}$ changes from $318 \mathrm{~K}$ to $448 \mathrm{~K}$. Though there is reduction in the collector efficiency, $\mathrm{T}_{5, \mathrm{p}}$ and $\eta_{T, p}$ increase when $\mathrm{T}_{\mathrm{H}}$ increases from $473 \mathrm{~K}$ to $523 \mathrm{~K}$.

Variations of VR for the SRC and ORC, and PR for the SRC are shown in Fig. 15. $\mathrm{T}_{5, \text { ch }}$ for a SE with built-in VR of 5 is $432 \mathrm{~K}$ with a corresponding PR of 5.8. For the ORC, single-stage turbine is sufficient for the power conversion because the VRs for the fluids are less than 30 .

Figs. 16 and 17 depict the variations of $\eta_{S R C}, \eta_{O R C}$ and $\eta_{T}$ with $\mathrm{T}_{5}$ when $\mathrm{T}_{\mathrm{H}}$ $=523 \mathrm{~K}$ and $\mathrm{T}_{\mathrm{L}}=293 \mathrm{~K}$. Due to the largest difference between $\mathrm{T}_{\mathrm{H}}$ and $\mathrm{T}_{\mathrm{L},} \eta_{T, p}$ of each fluid is the highest among the four cases. However, VRs at $\mathrm{T}_{5, \mathrm{ch}}$ for the ORC is large, as shown in Fig. 18. From this viewpoint, off-design operation of the SE in which $\mathrm{T}_{5, \mathrm{op}}<\mathrm{T}_{5, \mathrm{ch}}$, not only provides a higher $\eta_{T}$ but also enables an easier design of the ORC turbine. For example, when $\mathrm{T}_{5}$ changes from $432 \mathrm{~K}$ to $390 \mathrm{~K}$, VR for the turbine using cyclohexane decreases from about 61.6 to 23.9. While the PR for the SE increases from about 5.8 to 18.8 . The SE should be capable to maintain an efficiency higher than $90 \%$ of the design value according to its characteristics [38]. 
$\mathrm{T}_{5, \mathrm{P}}$ and $\eta_{T, P}$ at the peak points for $\mathrm{T}_{\mathrm{H}}=473 \mathrm{~K}$ and $\mathrm{T}_{\mathrm{L}}=313 \mathrm{~K}, \mathrm{~T}_{\mathrm{H}}=473 \mathrm{~K}$ and $\mathrm{T}_{\mathrm{L}}$ $=293 \mathrm{~K}, \mathrm{~T}_{\mathrm{H}}=523 \mathrm{~K}$ and $\mathrm{T}_{\mathrm{L}}=313 \mathrm{~K}, \mathrm{~T}_{\mathrm{H}}=523 \mathrm{~K}$ and $\mathrm{T}_{\mathrm{L}}=293 \mathrm{~K}$ are summarized in Table 6.

\subsection{Exergetic analysis}

To reveal the thermodynamic irreversibility of the DSG solar thermal power generation system, a case is presented in Table 7. The ORC evaporation temperature in the table might not have the optimum value, but the table offers a view of the exergy destruction in the elements of the PTC-SORC system. The total electricity output of the system is $100 \mathrm{~kW}$. Cyclohexane is used as the ORC fluid. As mentioned above, off-design operation of the SE is beneficial to the system efficiency and ORC turbine design, and thus the selected ORC evaporation temperature is lower than $\mathrm{T}_{5, \text { ch. }}$. A SE efficiency of 0.68 is assumed for the operating PR of 15 . This value is consistent with the experiment result [38]. Other device efficiencies are the same as those in Table 5. The exergy loss in PTC occupies the majority of total exergy losses (76.39-83.61\%). The exergy losses associated with HX1, HX2, turbine and SE are close, while the losses in the pumps are slight. A regenerator in the ORC will be able to reduce the exergy destruction in $\mathrm{HX} 1$ and $\mathrm{HX} 2$ regarding the degree of superheat at the turbine outlet of about 22-43 K. Excluding the loss in PTC, the exergy losses in the SORC range from $62.24 \mathrm{~kW}$ to $65.36 \mathrm{~kW}$, which are about $60 \%$ of the total electricity generated. The overall exergetic efficiency of the system is from $19.24 \%$ to $21.40 \%$.

\section{Conclusion}


The good applicability in power conversion with steam-liquid mixture makes the SE suitable for utilization of low-medium temperature heat source. The long term usage in waste heat recovery and geothermal power industries underscores the potential of SE in distributed solar power generation. The PTC-SORC system based on steam SE has advantages over conventional PTC-SRC system regarding the lower pressure and temperature in the solar field, lower technical requirement in heat storage and better reaction to low ambient temperature. It is also more advantageous than PTC-ORC system because the concerns on thermal instability, flammability, and low thermodynamic performance of organic fluids at temperature above $473 \mathrm{~K}$ are eased. By employing the heat storage unit, the PTC-SORC system is able to generate power steadily under fluctuating solar radiation without any secondary HTF.

Energetic and exergetic investigation on the PTC-SORC system is conducted. Following conclusions can be drawn:

(1) Given the hot /cold side temperatures, there are an ORC evaporation temperature $\left(T_{5, p}\right)$ at which system efficiency is theoretically maximized, and an ORC evaporation temperature $\left(\mathrm{T}_{5, \mathrm{ch}}\right)$ enabling the best $\mathrm{SE}$ behavior. Due to the low built-in VR of SE, the practical ORC evaporation temperature shall be higher than $T_{5, p}$ and lower than $T_{5, \text { ch }}$ Off-design operation of the SE seems unavoidable for the sake of higher system efficiency and simpler ORC turbine.

(2) With SE efficiency of 0.68 , turbine efficiency of 0.75 and ORC fluid of cyclohexane, solar thermal power efficiency of $13.68 \%, 15.03 \%, 14.74 \%$ and $15.62 \%$ can be achieved at hot /cold side temperatures of 473/313 K, 473/293 
$\mathrm{K}, 523 / 313 \mathrm{~K}$ and 523/293 $\mathrm{K}$, respectively. The main exergy destruction occurs in the solar collectors, which amounts to approximately $80 \%$ of the total exergy destruction in the system. The exergy losses in the turbine, SE, ORC evaporator (i.e. SRC condenser) and ORC condenser are comparable. The ratio of the exergy losses in the four elements to the net electricity output is around $60 \%$. The system exergetic efficiency ranges from $19.24 \%$ to $21.40 \%$.

\section{Acknowledgment}

This study was sponsored by the National Science Foundation of China (51476159, 51378483, 51206154, 51178442), Fundamental Research Funds for the Central Universities of China and Dongguan Innovative Research Team Program (2014607101008).

\section{REFERENCE}

[1] List of solar thermal power stations.

<http://en.wikipedia.org/wiki/List_of_solar_thermal_power_stations> [22.09.15].

[2] Birnbaum J, Eck M, Fichtner M, Hirsch T, Lehmann D, Zimmermann G. A direct 
steam generation solar power plant with integrated thermal storage. Journal of Solar Energy Engineering. 2010;132:031014.

[3] Laing D, Bahl C, Bauer T, Lehmann D, Steinmann W-D. Thermal energy storage for direct steam generation. Solar Energy. 2011;85:627-33.

[4] Montes M, Rovira A, Muñoz M, Martínez-Val J. Performance analysis of an integrated solar combined cycle using direct steam generation in parabolic trough collectors. Applied Energy. 2011;88:3228-38.

[5] Eck M, Hirsch T. Dynamics and control of parabolic trough collector loops with direct steam generation. Solar Energy. 2007;81:268-79.

[6] Giostri A, Binotti M, Astolfi M, Silva P, Macchi E, Manzolini G. Comparison of different solar plants based on parabolic trough technology. Solar Energy. 2012;86:1208-21.

[7] Eck M, Steinmann W-D. Direct steam generation in parabolic troughs: first results of the DISS project. Journal of solar energy engineering. 2002;124:134-9.

[8] Zarza E, Valenzuela L, León J, Weyers H-D, Eickhoff M, Eck M, et al. The DISS project: direct steam generation in parabolic trough systems. Operation and maintenance experience and update on project status. Journal of solar energy engineering. 2002;124:126-33.

[9] Alguacil M, Prieto C, Rodriguez A, Lohr J. Direct steam generation in parabolic trough collectors. Energy Procedia. 2014;49:21-9.

[10] Ochoa LR. Engineering Aspects of a Parabolic Trough Collector Field with Direct Steam Generation and an Organic Rankine Cycle. Master of Science in Energy 
Systems, Cologne, Germany, October 2014.

[11] Pitz-Paal R, Dersch J, Milow B, Ferriere A, Romero M, Tellez F, et al. ECOSTAR roadmap document. DLR, Germany. 2005.

[12] Zarza E, Rojas ME, González L, Caballero JM, Rueda F. INDITEP: The first pre-commercial DSG solar power plant. Solar Energy. 2006;80:1270-6.

[13] Lei D, Wang Z, Du F. The glass-to-metal sealing process in parabolic trough solar receivers. Proceedings of ISES World Congress 2007 (Vol I-Vol V): Springer; 2009. p. $740-4$.

[14] Price H, Lupfert E, Kearney D, Zarza E, Cohen G, Gee R, et al. Advances in parabolic trough solar power technology. Journal of solar energy engineering. 2002;124:109-25.

[15] Kearney D, Herrmann U, Nava P, Kelly B, Mahoney R, Pacheco J, et al. Assessment of a molten salt heat transfer fluid in a parabolic trough solar field. Journal of solar energy engineering. 2003;125:170-6.

[16] World's largest solar thermal plant with storage comes online. < http://cleantechnica.com/2013/10/14/worlds-largest-solar-thermal-plant-storage-come s-online/ > [05.10.15].

[17] Prabhu E. Solar trough organic rankine electricity system (stores) stage 1: Power plant optimization and economics. US National Renewable Energy Laboratory, Golden, CO, Technical Report No NREL/SR-550-39433. 2006.

[18] Zhai H, Dai Y, Wu J, Wang R. Energy and exergy analyses on a novel hybrid solar heating, cooling and power generation system for remote areas. Applied Energy. 
2009;86:1395-404.

[19] Bouvier J-L, Michaux G, Salagnac P, Nepveu F, Rochier D, Kientz T. Experimental characterisation of a solar parabolic trough collector used in a micro-CHP (micro-cogeneration) system with direct steam generation. energy. 2015;83:474-85.

[20] Glavatskaya Y, Podevin P, Lemort V, Shonda O, Descombes G. Reciprocating expander for an exhaust heat recovery rankine cycle for a passenger car application. Energies. 2012;5:1751-65.

[21] Engineering case. <www.jxhdep.com/en/newsInfo.asp?pid=4>.[20.05.15].

[22] Helix Power SEs. <www.heliexpower.com/category/news>.[30.09.15].

[23] Opcon's SEs. <www.opcon.se/web/oes_en.aspx>. [02.10.15].

[24] Smith I, Stosic N, Mujic E, Kovacevic A. Steam as the working fluid for power recovery from exhaust gases by means of screw expanders. Proceedings of the Institution of Mechanical Engineers, Part E: Journal of Process Mechanical Engineering. 2011;225:117-25.

[25] Angelino G, Invernizzi C, Molteni G. The potential role of organic bottoming Rankine cycles in steam power stations. Proceedings of the Institution of Mechanical Engineers, Part A: Journal of Power and Energy. 1999;213:75-81.

[26] Al-Sulaiman FA. Energy and sizing analyses of parabolic trough solar collector integrated with steam and binary vapor cycles. Energy. 2013;58:561-70.

[27] Steinmann W-D, Eck M. Buffer storage for direct steam generation. Solar Energy. 2006;80:1277-82. 
[28] Li J, Pei G, Ji J, Bai X, Li P, Xia L. Design of the ORC (organic Rankine cycle) condensation temperature with respect to the expander characteristics for domestic CHP (combined heat and power) applications. Energy. 2014;77:579-90.

[29] Fernández F, Prieto M, Suárez I. Thermodynamic analysis of high-temperature regenerative organic Rankine cycles using siloxanes as working fluids. Energy. 2011;36:5239-49.

[30] Drescher U, Brüggemann D. Fluid selection for the Organic Rankine Cycle (ORC) in biomass power and heat plants. Applied Thermal Engineering. 2007;27:223-8.

[31] Kruger D, Heller A, Hennecke K, Duer K. Parabolic trough collectors for district heating systems at high latitudes: a case study. Proceedings of Eurosun2000.

[32] Kalogirou SA. Solar thermal collectors and applications. Progress in energy and combustion science. 2004;30:231-95.

[33] Winter C-J, Sizmann RL, Vant-Hull LL. Solar power plants: fundamentals, technology, systems, economics: Springer Science \& Business Media; 2012.

[34] Avadhanula VK, Lin C-S. Empirical models for a screw expander based on experimental data from organic Rankine cycle system testing. Journal of Engineering for Gas Turbines and Power. 2014;136:062601.

[35] Wang W, Wu Y-t, Ma C-f, Xia G-d, Wang J-f. Experimental study on the performance of single screw expanders by gap adjustment. Energy. 2013;62:379-84.

[36] Read M, Stosic N, Smith IK. Optimization of Screw Expanders for Power Recovery From Low-Grade Heat Sources. Energy Technology \& Policy. 
2014;1:131-42.

[37] Hsu S-W, Chiang H-WD, Yen C-W. Experimental Investigation of the Performance of a Hermetic Screw-Expander Organic Rankine Cycle. Energies. 2014;7:6172-85.

[38] $\mathrm{Ng} \mathrm{K}$, Bong $\mathrm{T}$, Lim $\mathrm{T}$. A thermodynamic model for the analysis of screw expander performance. Heat Recovery Systems and CHP. 1990;10:119-33.

[39] Ziviani D, Desideri A, Lemort V, De Paepe M, van den Broek M. Low-order models of a single-screw expander for organic Rankine cycle applications. IOP Conference Series: Materials Science and Engineering: IOP Publishing; 2015. p. 012061.

[40] Li J. Structural Optimization and Experimental Investigation of the Organic Rankine Cycle for Solar Thermal Power Generation: Springer; 2014.

[41] Macchi E, Perdichizzi A. Efficiency prediction for axial-flow turbines operating with nonconventional fluids. Journal of Engineering for Gas Turbines and Power. $1981 ; 103: 718-24$.

[42] Invernizzi C, Iora P, Silva P. Bottoming micro-Rankine cycles for micro-gas turbines. Applied thermal engineering. 2007;27:100-10.

[43] Shu G, Li X, Tian H, Liang X, Wei H, Wang X. Alkanes as working fluids for high-temperature exhaust heat recovery of diesel engine using organic Rankine cycle. Applied Energy. 2014;119:204-17. 


\section{Figure Legend}

Fig.1. Schematic diagram of the PTC-SORC system

Fig. 2. $T$-s diagram of an ideal cascade Rankine cycle

Fig. 3. $T$-s diagram of the SORC

Fig.4. SRC power efficiency variation with the turbine inlet temperature

Fig. 5. Efficiency variations of $\mathrm{SRC}$ and $\mathrm{ORC}$ with $\mathrm{T}_{5}$ when $\mathrm{T}_{\mathrm{H}}=473 \mathrm{~K}$ and $\mathrm{T}_{\mathrm{L}}=313$

K

Fig. 6. Efficiency variation of $\mathrm{SORC}$ with $\mathrm{T}_{5}$ when $\mathrm{T}_{\mathrm{H}}=473 \mathrm{~K}$ and $\mathrm{T}_{\mathrm{L}}=313 \mathrm{~K}$

Fig. 7. Variation of solar thermal power efficiency with $T_{5}$ when $T_{H}=473 \mathrm{~K}$ and $T_{L}$ $=313 \mathrm{~K}$

Fig. 8. Variations of screw expander isentropic efficiency with pressure ratio or pressure difference: test results by (a) Avadhanula et al. [34]; (b) NG et al. [38]; (c) Matthew et al. [36]; (d) Sung et al. [37]

Fig. 9. Variations of VR for SRC and ORC, and PR for $S R C$ with $T_{5}$ when $T_{H}=473 \mathrm{~K}$ and $\mathrm{T}_{\mathrm{L}}=313 \mathrm{~K}$

Fig. 10. Efficiency variations of $S R C$ and $O R C$ with $T_{5}$ when $T_{H}=473 \mathrm{~K}$ and $T_{L}=293$ $\mathrm{K}$

Fig. 11. Variation of solar thermal power efficiency with $T_{5}$ when $T_{H}=473 \mathrm{~K}$ and $T_{L}$ $=293 \mathrm{~K}$

Fig. 12. Variation of VR for ORC with $T_{5}$ when $T_{H}=473 \mathrm{~K}$ and $T_{L}=293 \mathrm{~K}$ Fig. 13. Efficiency variations of $\mathrm{SRC}$ and $\mathrm{ORC}$ with $\mathrm{T}_{5}$ when $\mathrm{T}_{\mathrm{H}}=523 \mathrm{~K}$ and $\mathrm{T}_{\mathrm{L}}=313$ $\mathrm{K}$ 
Fig. 14. Variation of solar thermal power efficiency with $T_{5}$ when $T_{H}=523 \mathrm{~K}$ and $T_{L}$ $=313 \mathrm{~K}$

Fig. 15. Variations of VR for $\mathrm{SRC}$ and $\mathrm{ORC}$, and $\mathrm{PR}$ for $\mathrm{SRC}$ with $\mathrm{T}_{5}$ when $\mathrm{T}_{\mathrm{H}}=523$

$\mathrm{K}$ and $\mathrm{T}_{\mathrm{L}}=313 \mathrm{~K}$

Fig. 16. Efficiency variations of SRC and ORC with $\mathrm{T}_{5}$ when $\mathrm{T}_{\mathrm{H}}=523 \mathrm{~K}$ and $\mathrm{T}_{\mathrm{L}}=293$

$\mathrm{K}$

Fig. 17. Variation of solar thermal power efficiency with $T_{5}$ when $T_{H}=523 \mathrm{~K}$ and $T_{L}$ $=293 \mathrm{~K}$

Fig. 18. Variation of VR for ORC with $T_{5}$ when $T_{H}=523 \mathrm{~K}$ and $T_{L}=293 \mathrm{~K}$

\section{Table legend}

Table 1. Some steam screw expander-based power plants in operation [22-24]

Table 2. Comparison of SRC and ORC power efficiency under different conditions, unit: $\%$

Table 3. Thermodynamic and environmental data for organic fluids

Table 4. Fixed parameters for calculation

Table 5. Exergy losses in each individual component

Table 6. Theoretical optimum ORC evaporation temperature and the corresponding solar thermal power efficiency

Table 7. Parameters distribution and exergy losses of the SORC system for producing $100 \mathrm{~kW}$ electricity 


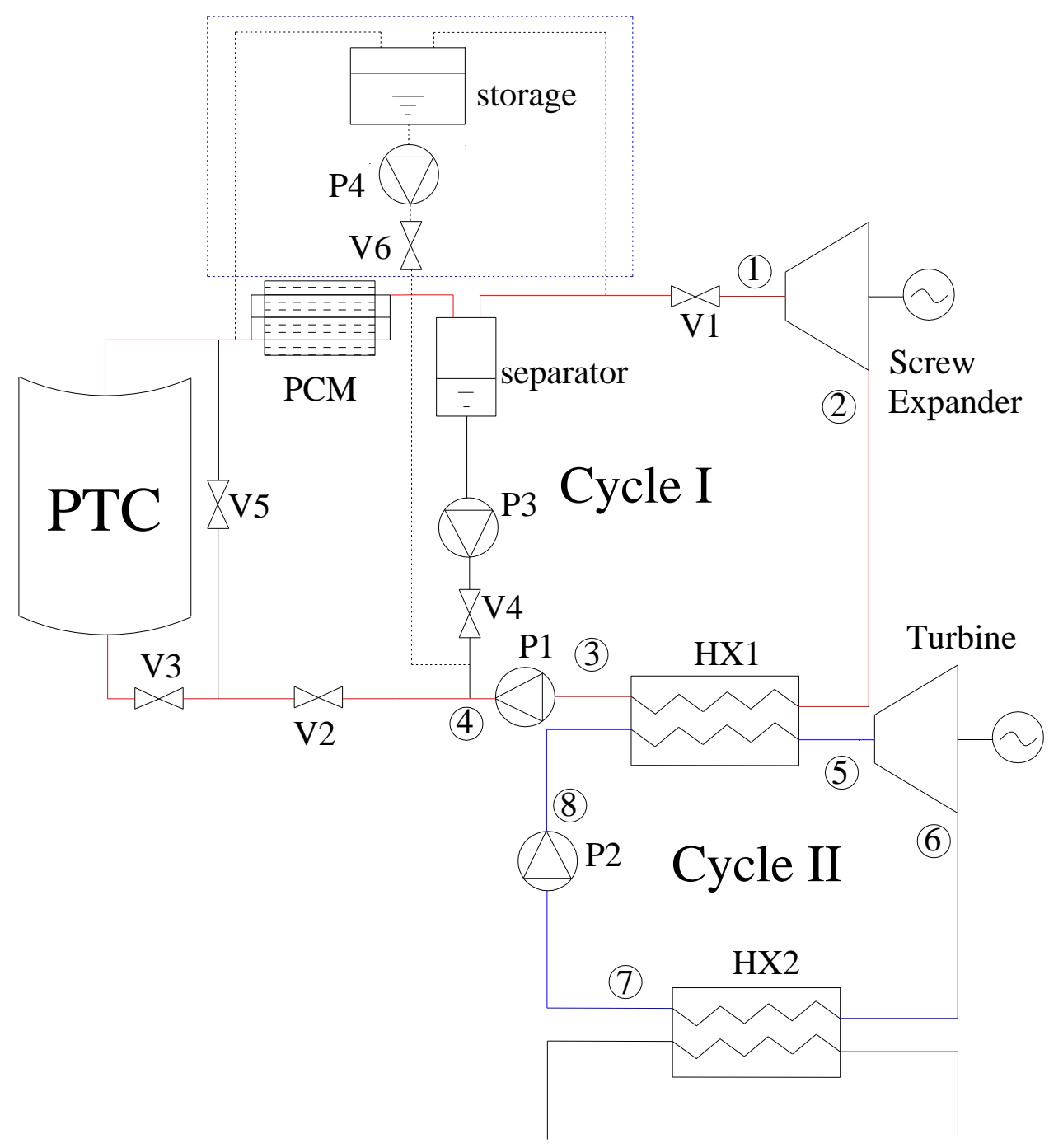

Fig.1. Schematic diagram of the PTC-SORC system 


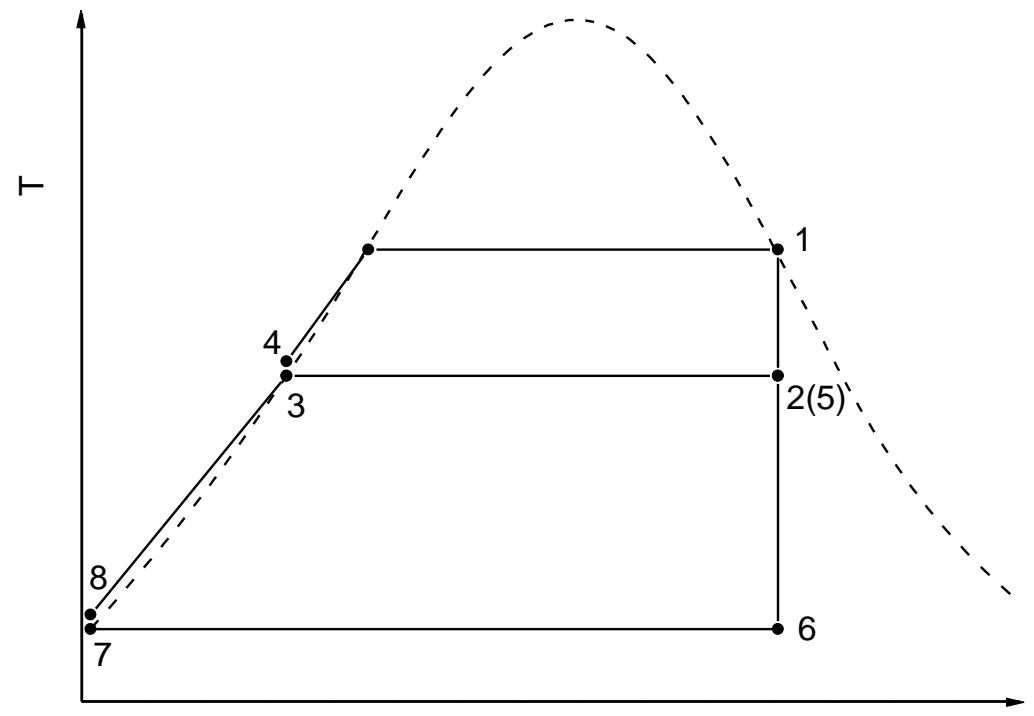

S

Fig. 2. $T$-s diagram of an ideal cascade Rankine cycle

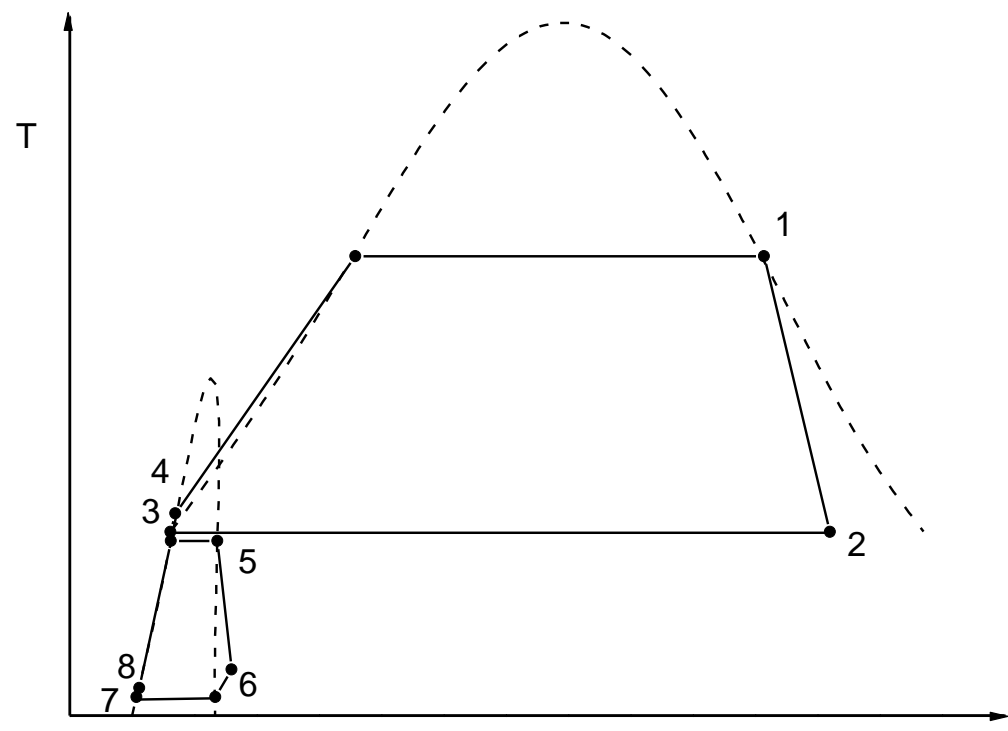

$S$

Fig. 3. $T-$ s diagram of the SORC 


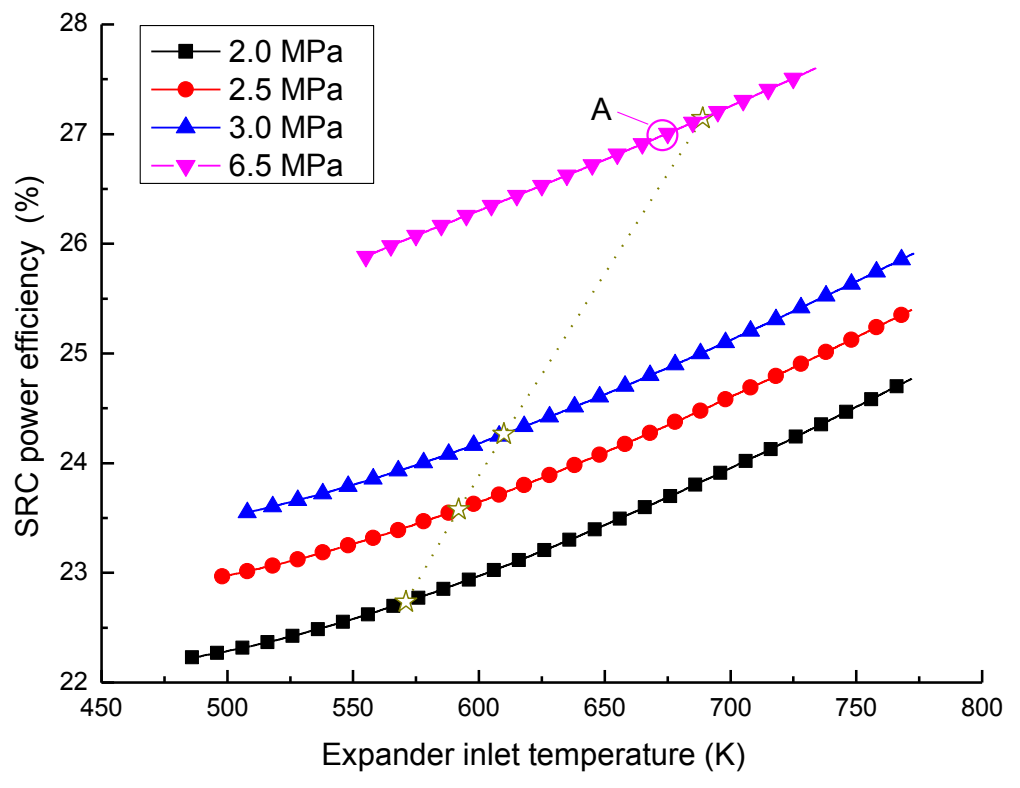

Fig.4. SRC power efficiency variation with the turbine inlet temperature

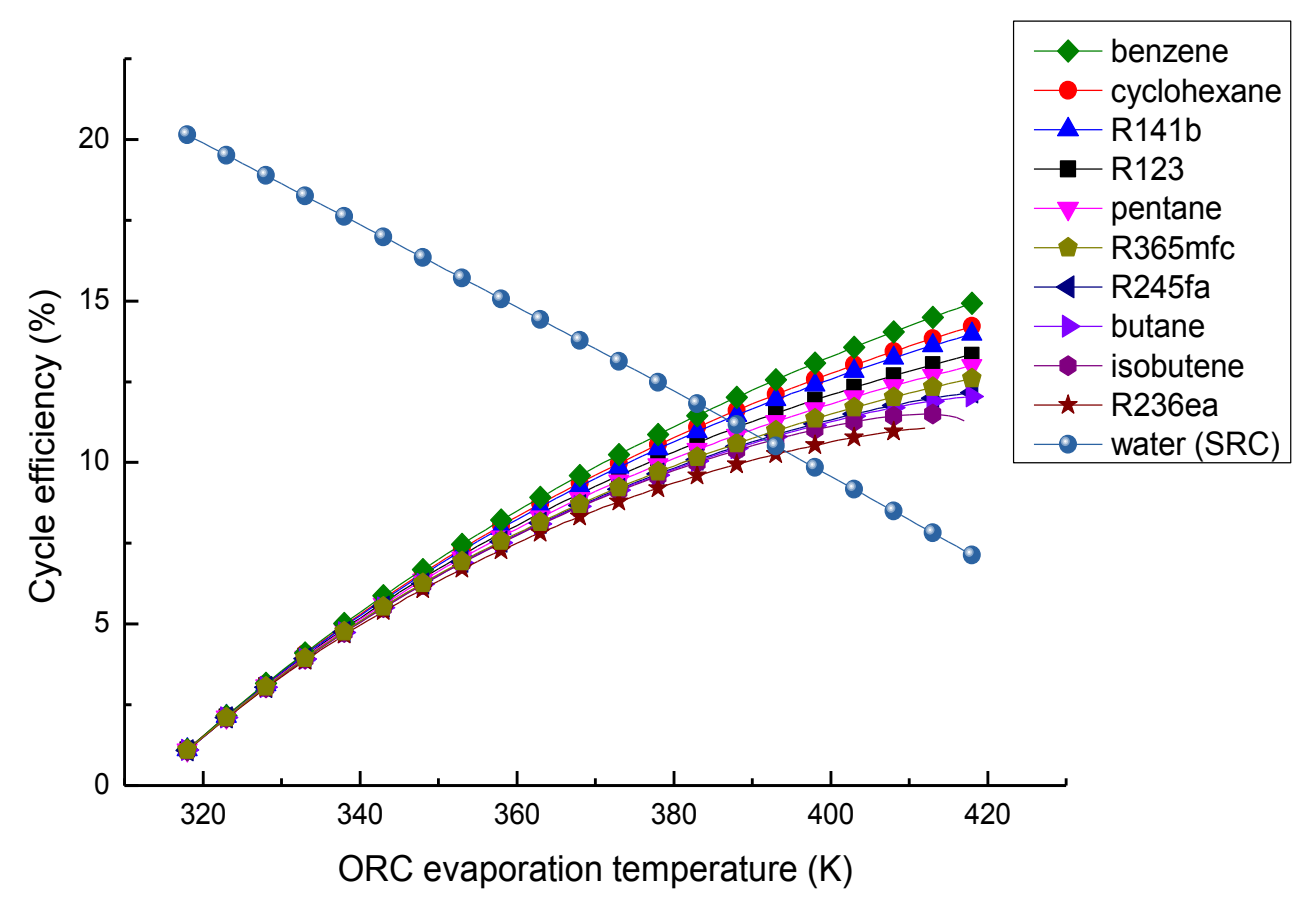

Fig. 5. Efficiency variations of $\mathrm{SRC}$ and $\mathrm{ORC}$ with $\mathrm{T}_{5}$ when $\mathrm{T}_{\mathrm{H}}=473 \mathrm{~K}$ and $\mathrm{T}_{\mathrm{L}}=313$ 


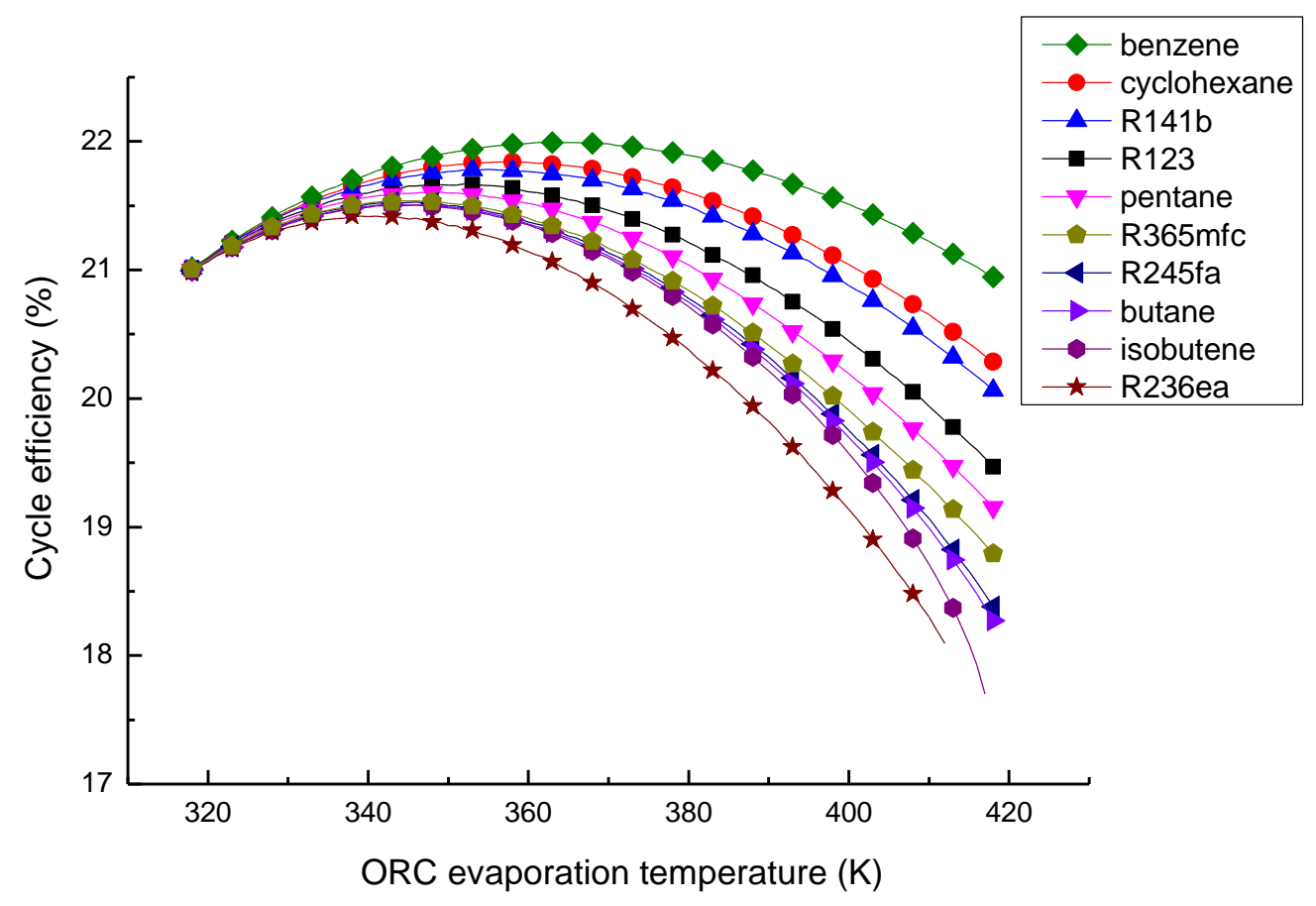

Fig. 6. Efficiency variation of $\mathrm{SORC}$ with $\mathrm{T}_{5}$ when $\mathrm{T}_{\mathrm{H}}=473 \mathrm{~K}$ and $\mathrm{T}_{\mathrm{L}}=313 \mathrm{~K}$

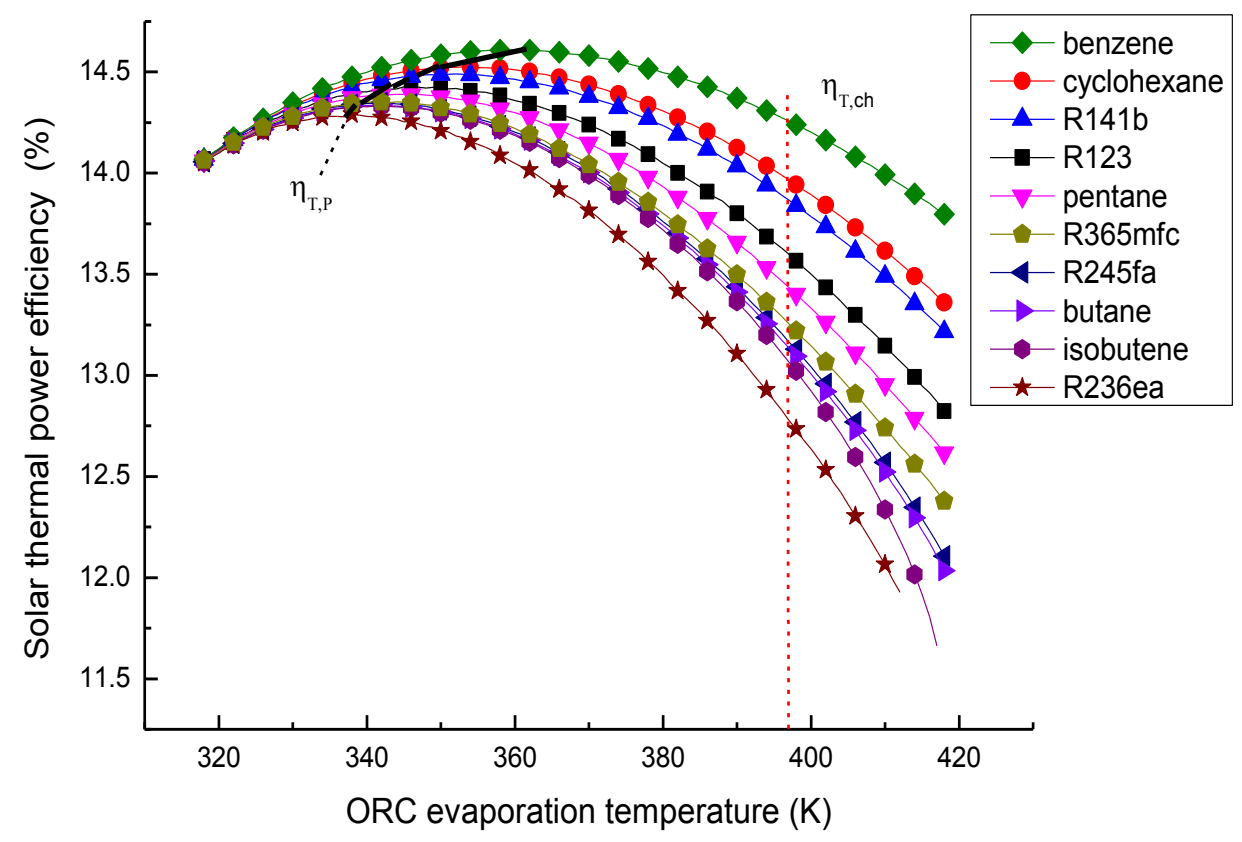

Fig. 7. Variation of solar thermal power efficiency with $T_{5}$ when $T_{H}=473 \mathrm{~K}$ and $T_{L}$

$$
=313 \mathrm{~K}
$$




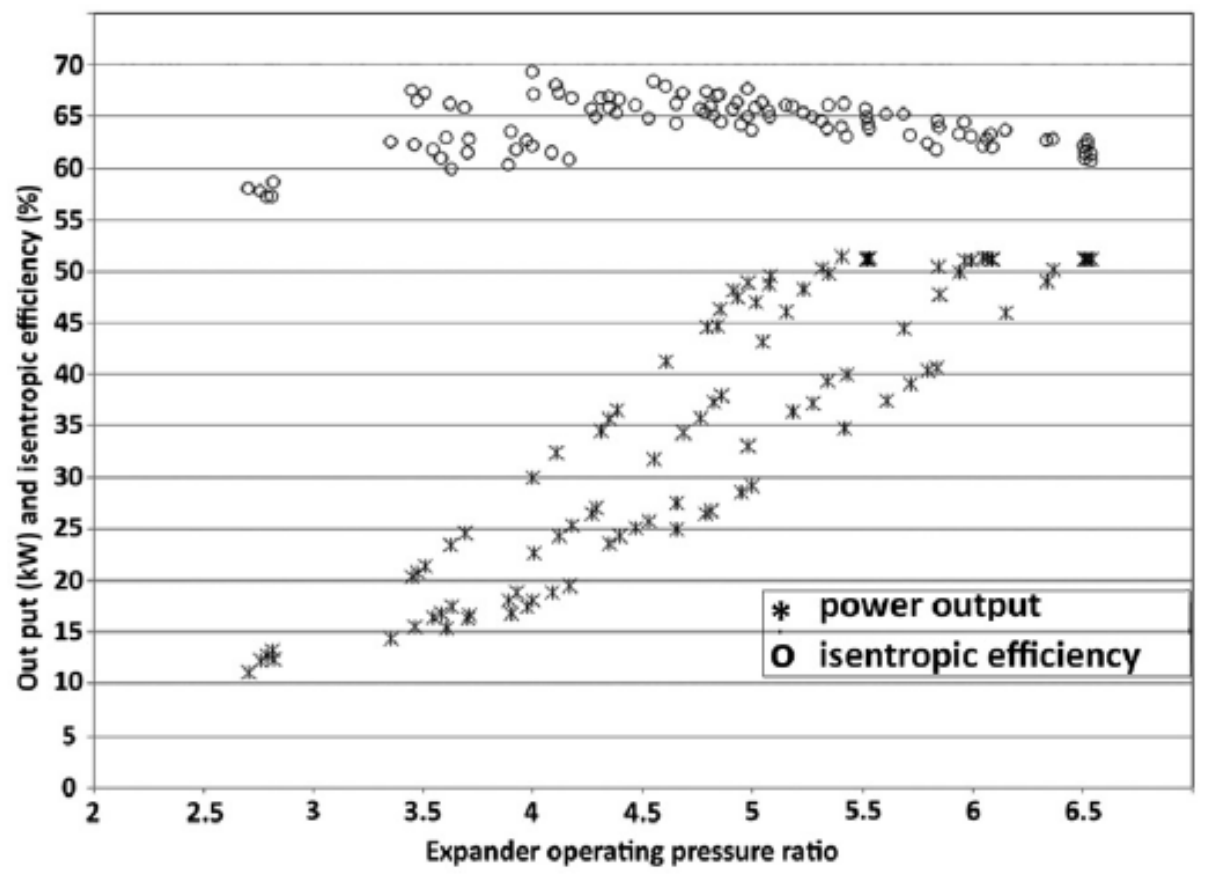

(a)

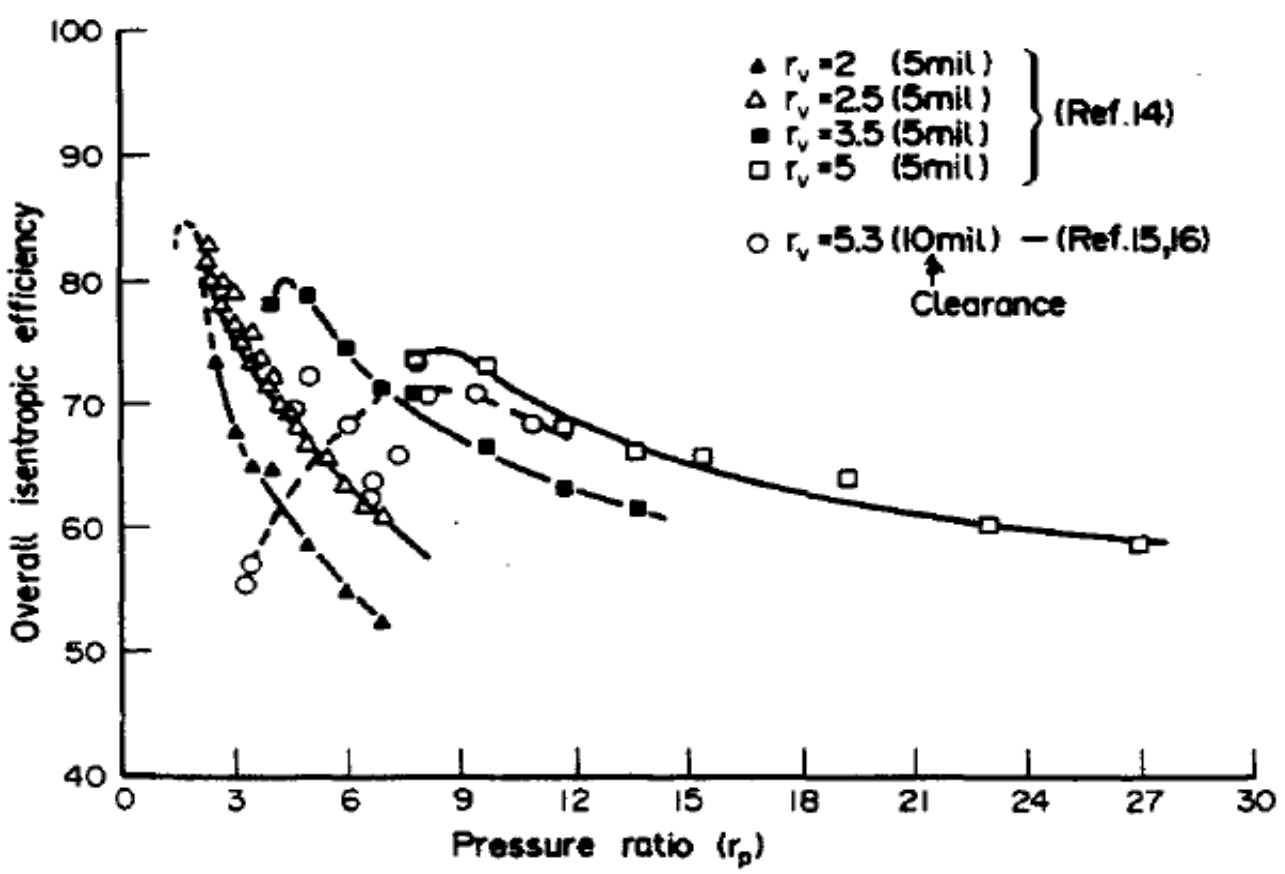

(b) 


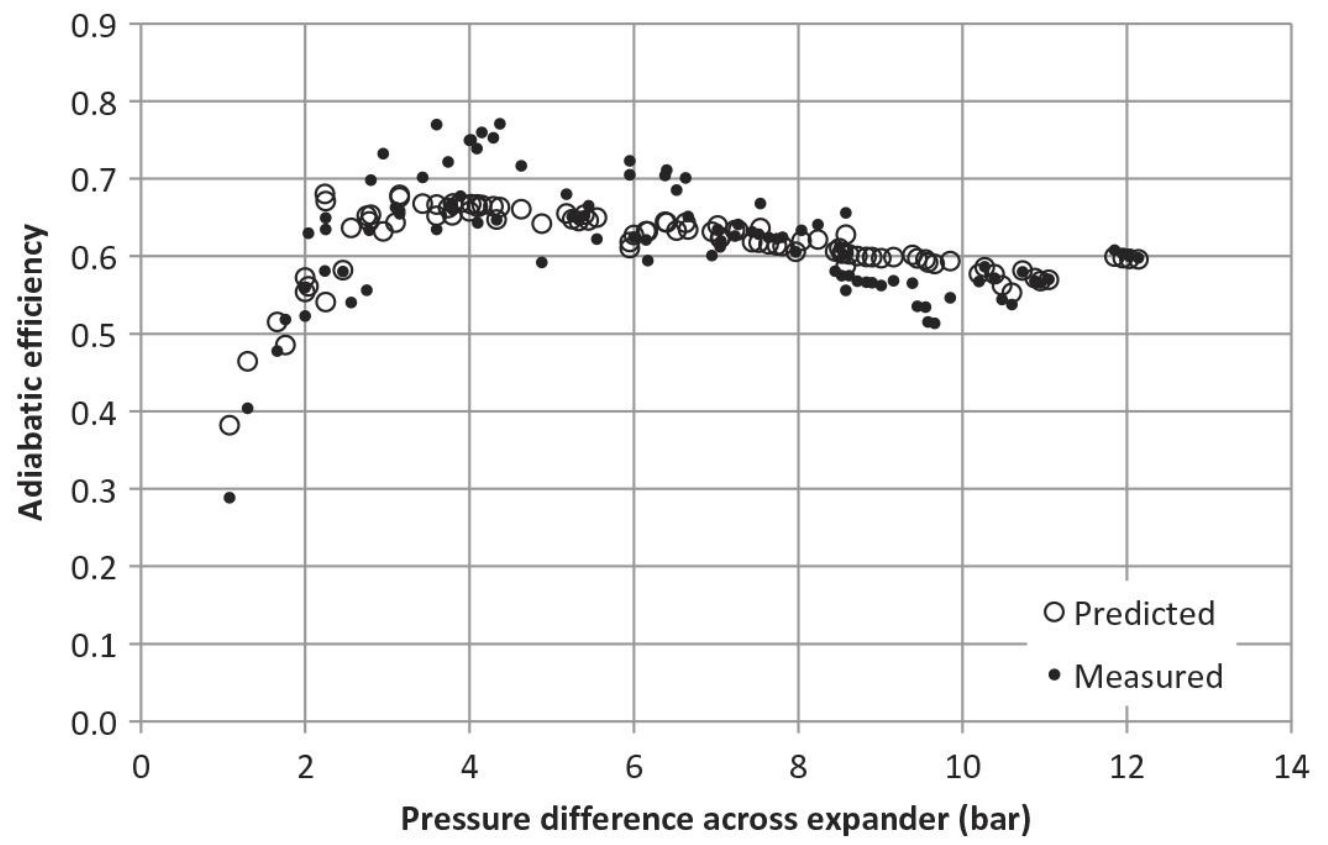

(c)

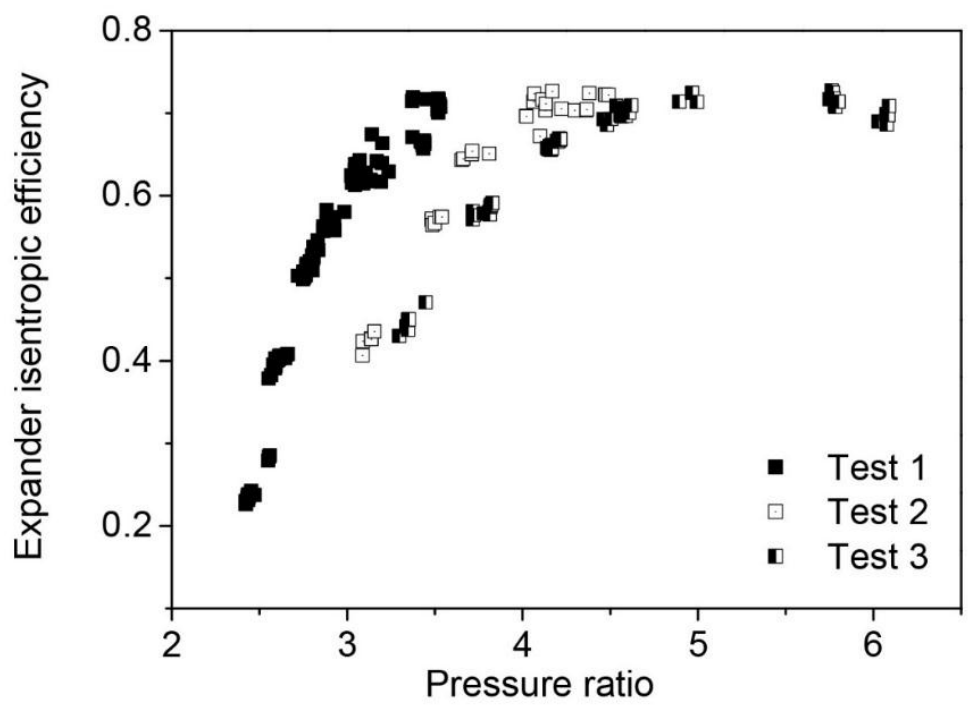

(d)

Fig. 8. Variations of screw expander isentropic efficiency with pressure ratio or pressure difference: test results by (a) Avadhanula et al. [34]; (b) NG et al. [38]; (c) Matthew et al. [36]; (d) Sung et al. [37] 


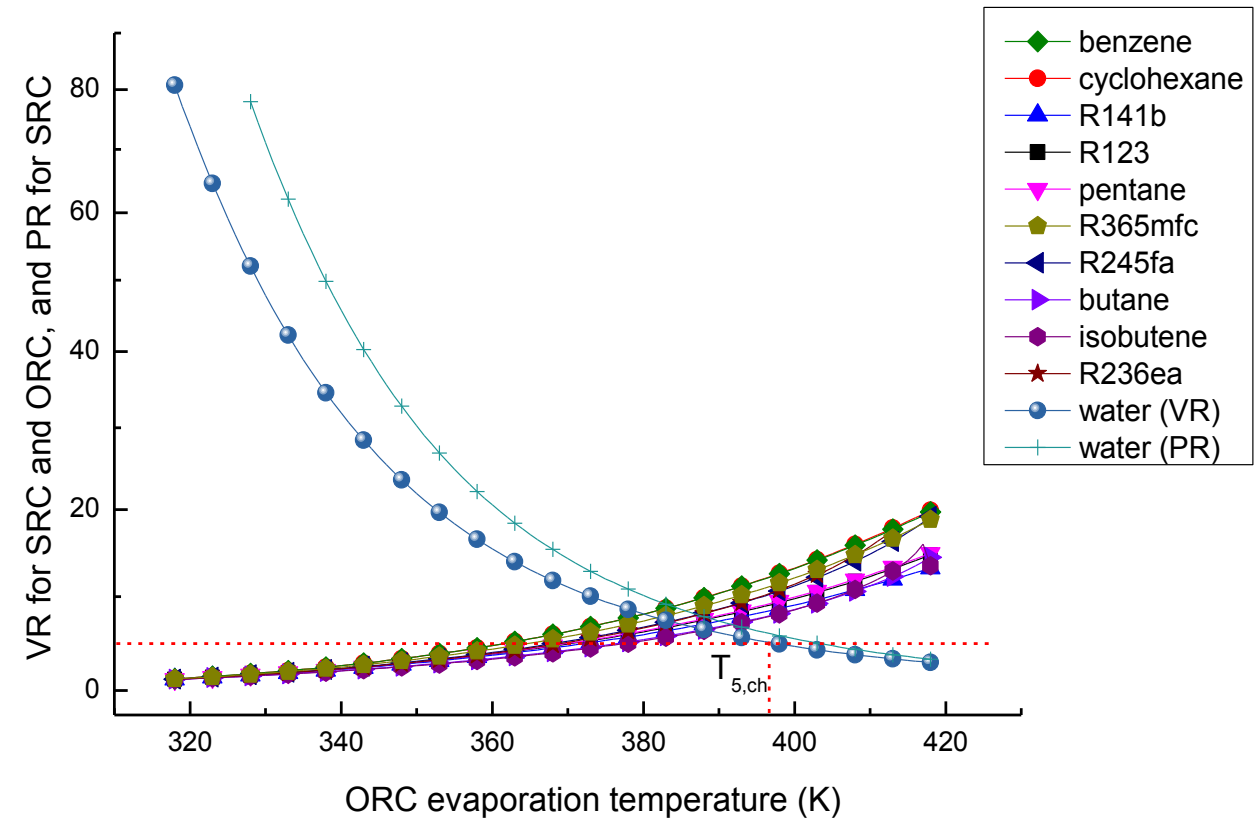

Fig. 9. Variations of VR for SRC and ORC, and PR for $S R C$ with $T_{5}$ when $T_{H}=473 \mathrm{~K}$ and $\mathrm{T}_{\mathrm{L}}=313 \mathrm{~K}$

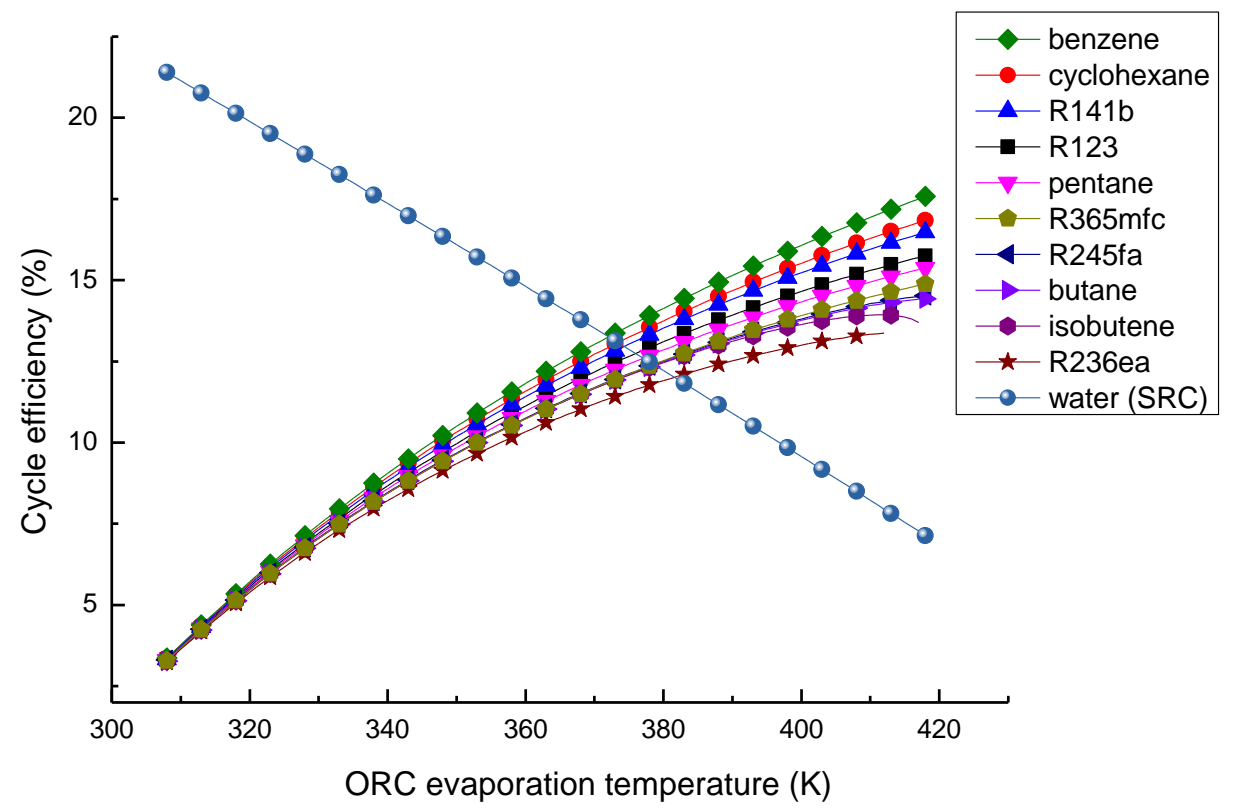

Fig. 10. Efficiency variations of $S R C$ and ORC with $T_{5}$ when $T_{H}=473 \mathrm{~K}$ and $T_{L}=293$ 


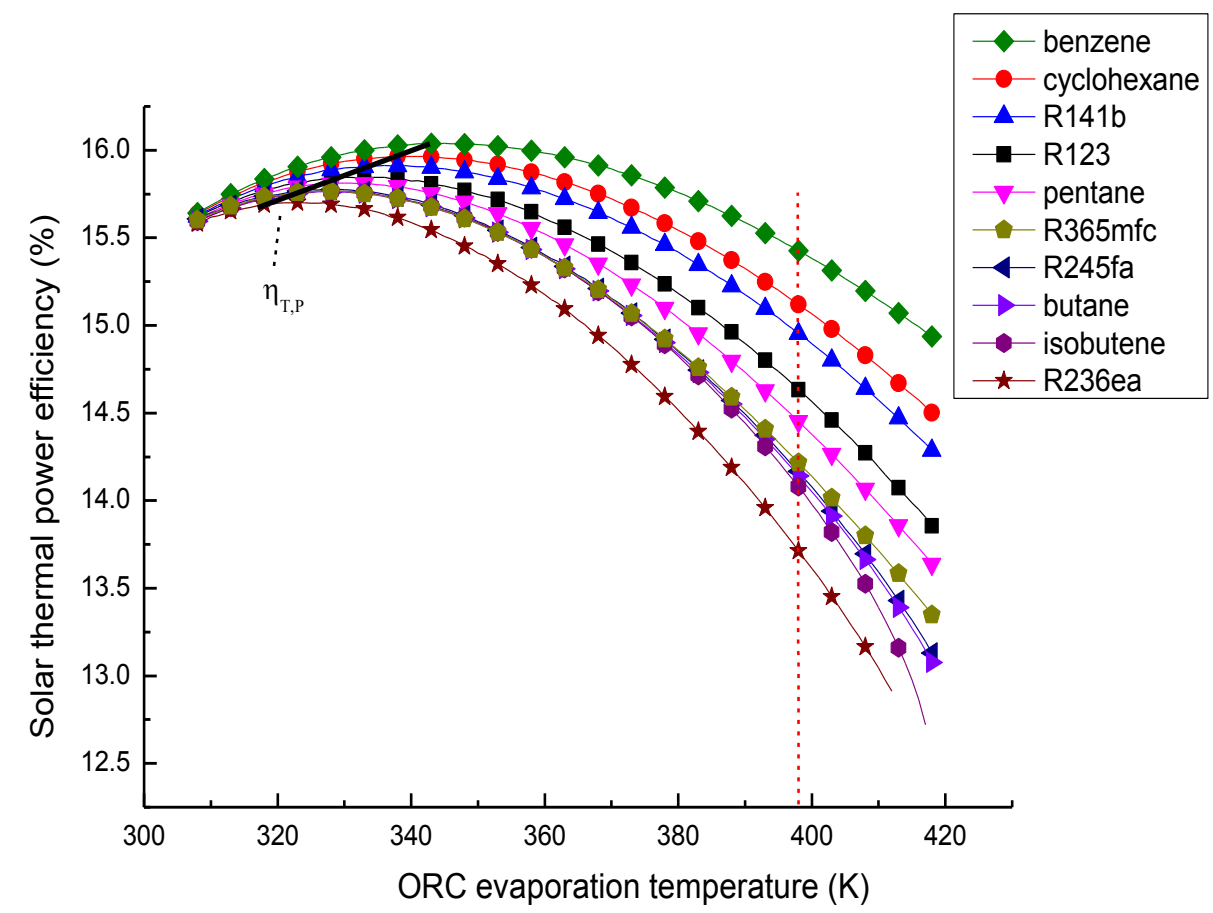

Fig. 11. Variation of solar thermal power efficiency with $T_{5}$ when $T_{H}=473 \mathrm{~K}$ and $T_{L}$

$$
=293 \mathrm{~K}
$$

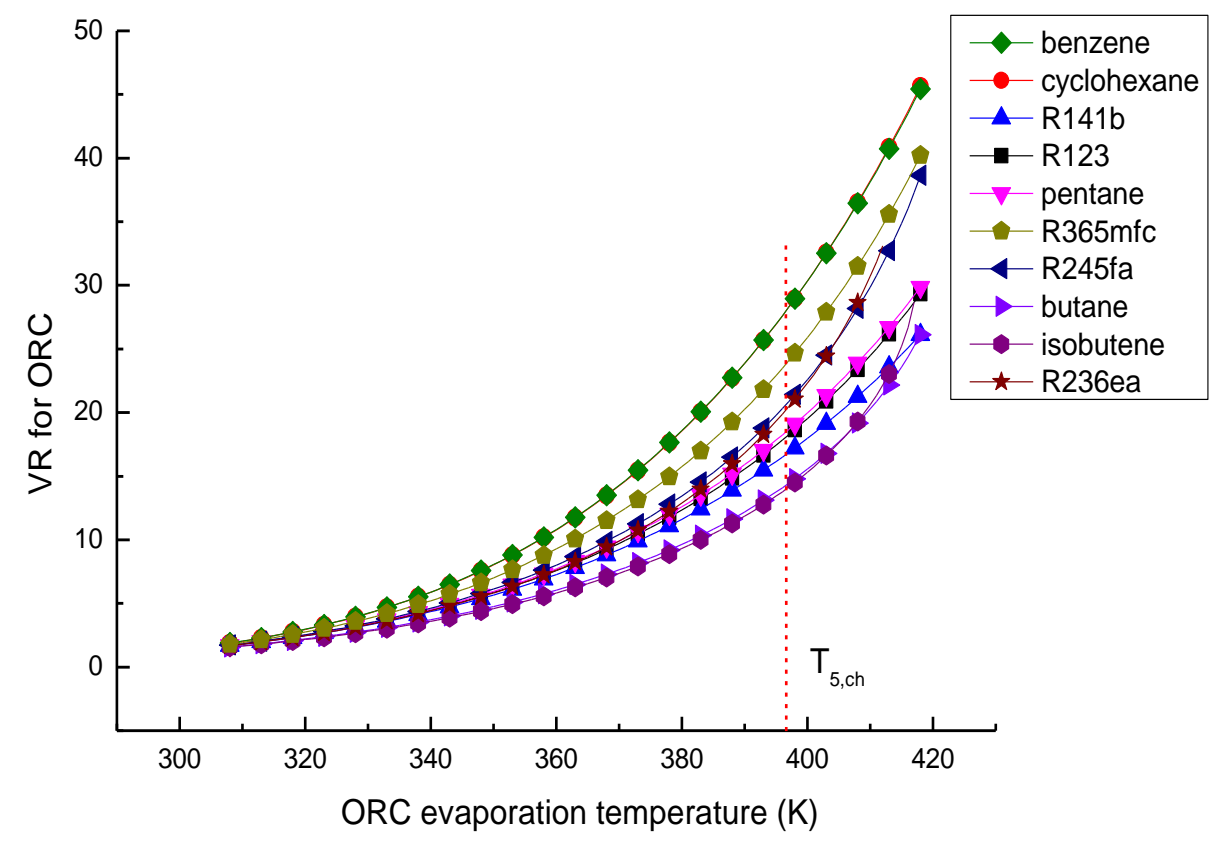

Fig. 12. Variations of VR for ORC with $T_{5}$ when $T_{H}=473 \mathrm{~K}$ and $T_{L}=293 \mathrm{~K}$ 


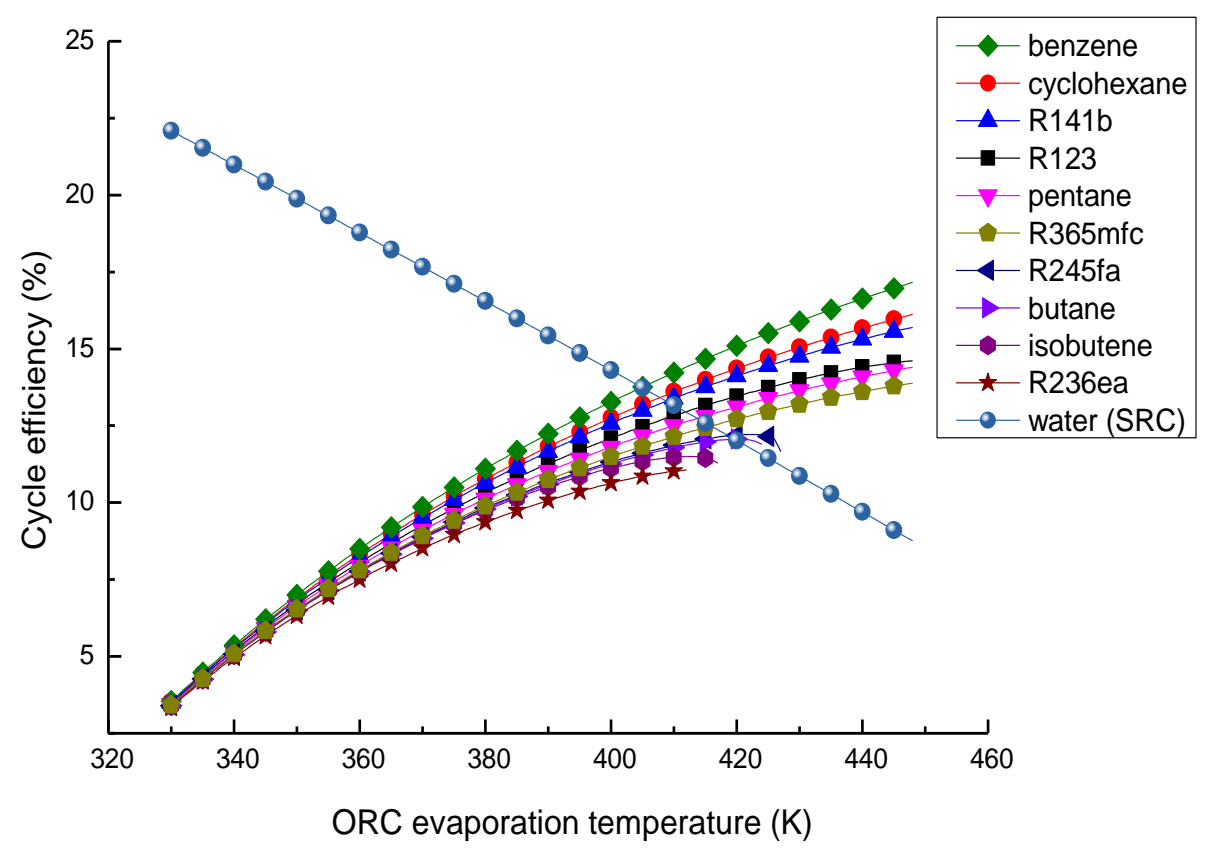

Fig. 13. Efficiency variations of $S R C$ and $O R C$ with $T_{5}$ when $T_{H}=523 \mathrm{~K}$ and $T_{L}=313$ K

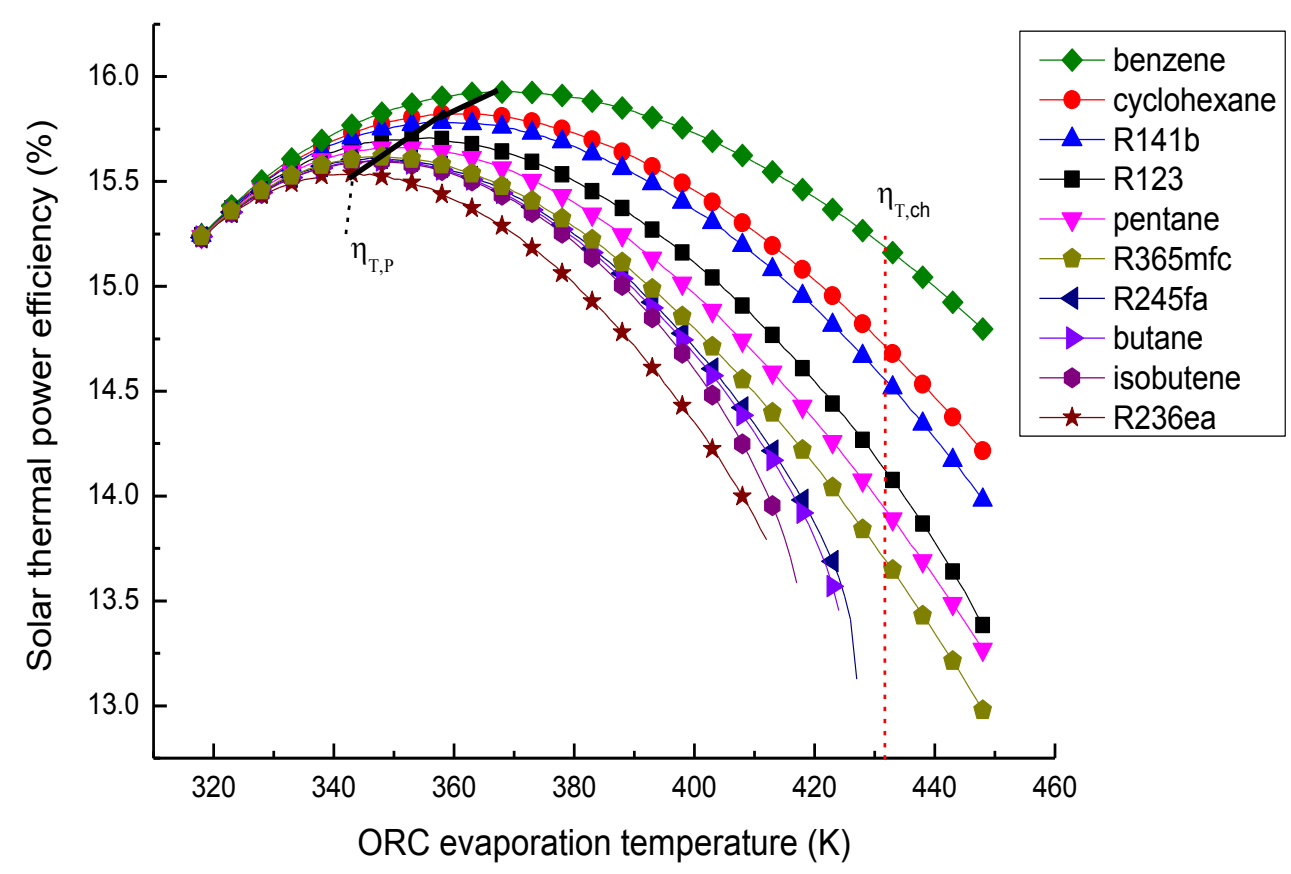

Fig. 14. Variation of solar thermal power efficiency with $T_{5}$ when $T_{H}=523 \mathrm{~K}$ and $T_{L}$

$$
=313 \mathrm{~K}
$$




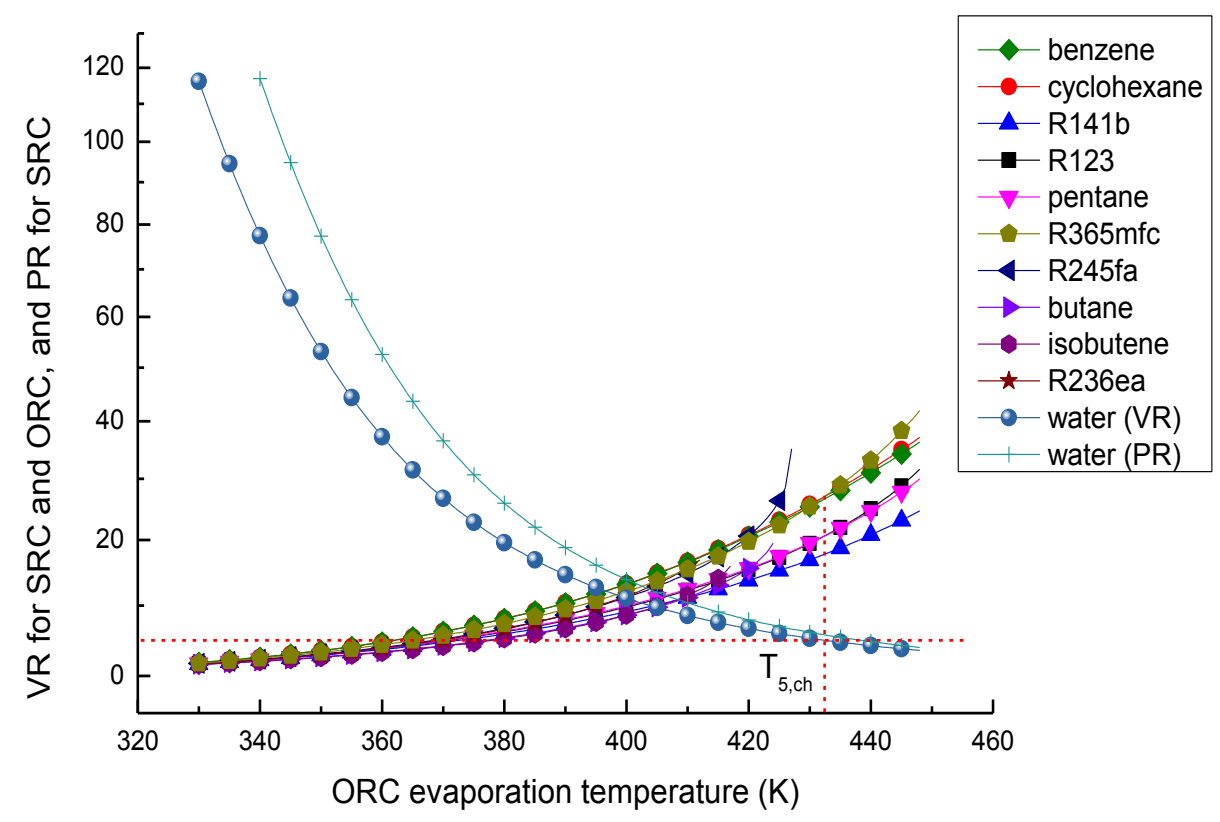

Fig. 15. Variations of VR for $\mathrm{SRC}$ and $\mathrm{ORC}$, and $\mathrm{PR}$ for $\mathrm{SRC}$ with $\mathrm{T}_{5}$ when $\mathrm{T}_{\mathrm{H}}=523$

$\mathrm{K}$ and $\mathrm{T}_{\mathrm{L}}=313 \mathrm{~K}$

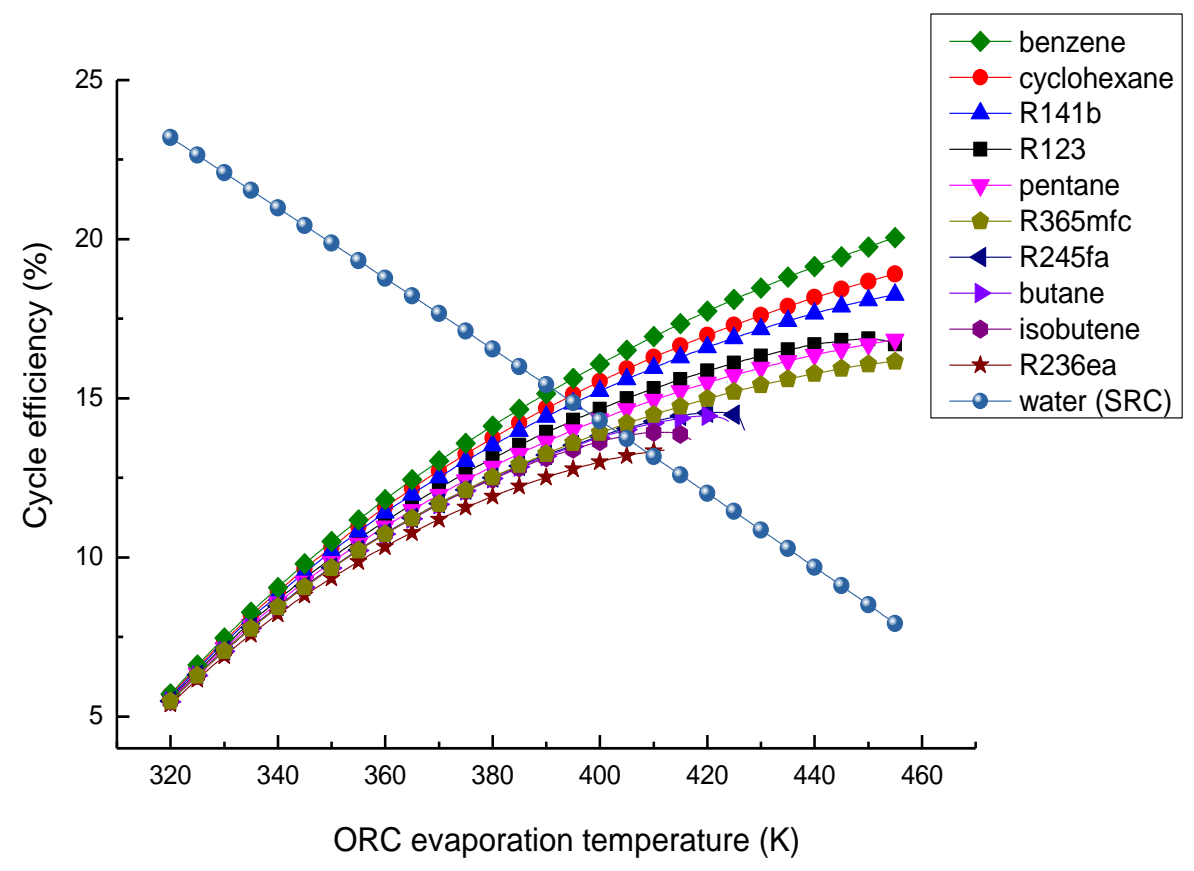

Fig. 16. Efficiency variations of $\mathrm{SRC}$ and $\mathrm{ORC}$ with $\mathrm{T}_{5}$ when $\mathrm{T}_{\mathrm{H}}=523 \mathrm{~K}$ and $\mathrm{T}_{\mathrm{L}}$

$=293 \mathrm{~K}$ 


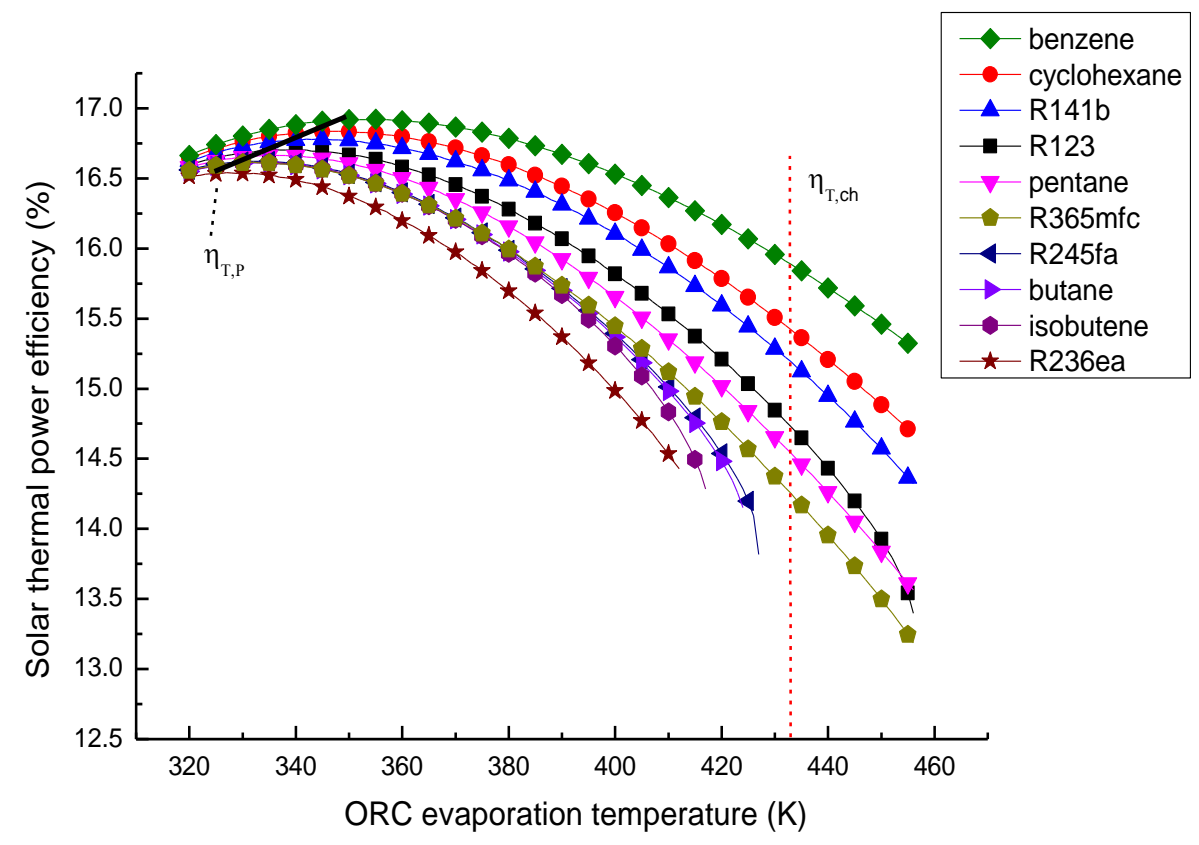

Fig. 17. Variation of solar thermal power efficiency with $T_{5}$ when $T_{H}=523 \mathrm{~K}$ and $T_{L}$ $=293 \mathrm{~K}$

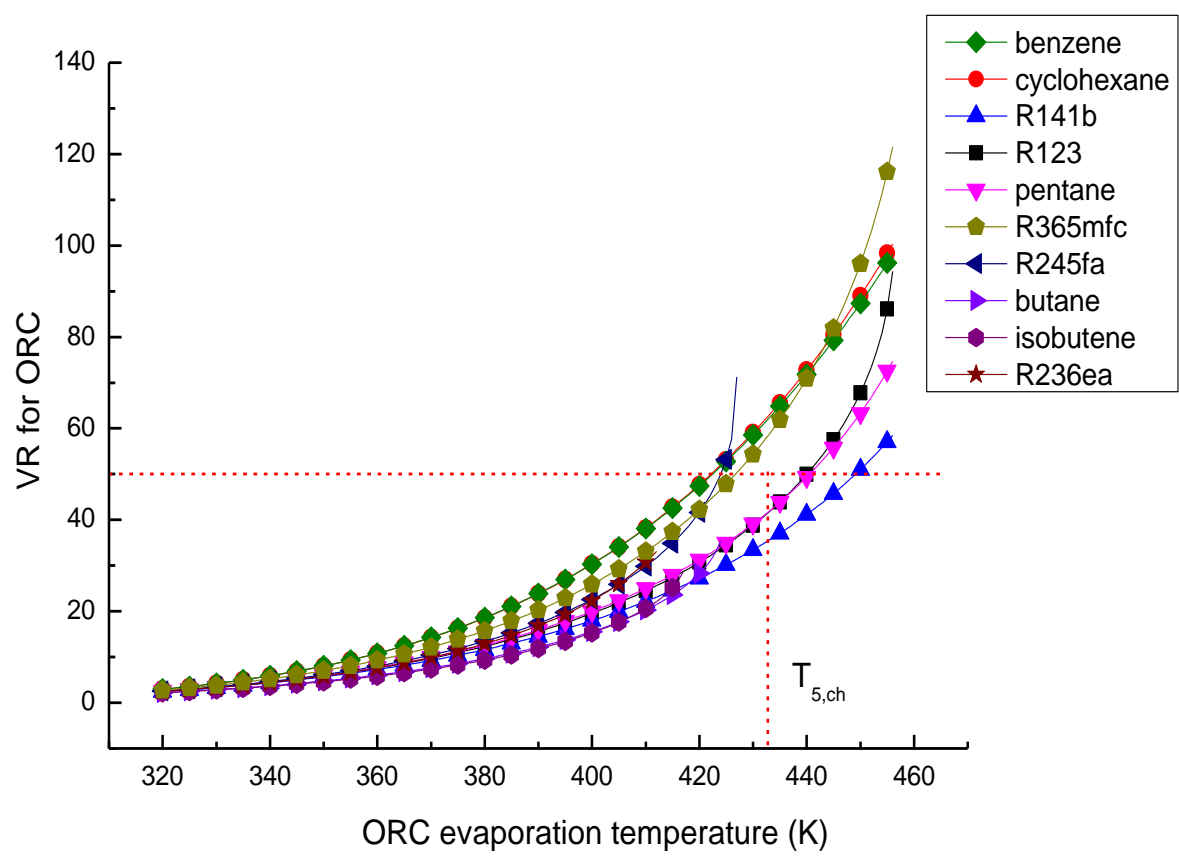

Fig. 18. Variation of VR for ORC with $T_{5}$ when $T_{H}=523 \mathrm{~K}$ and $T_{L}=293 \mathrm{~K}$ 
Table 1. Some steam screw expander-based power plants in operation [21-23]

\begin{tabular}{|c|c|c|c|c|c|}
\hline Location & Started & Heat source & $\begin{array}{l}\text { Capacity, } \\
\text { MW }\end{array}$ & $\begin{array}{l}\text { SE inlet } \\
\text { pressure, MPa }\end{array}$ & $\begin{array}{l}\text { SE inlet } \\
\text { temperature, } \mathrm{K}\end{array}$ \\
\hline $\begin{array}{l}\text { Yangbajin, } \\
\text { China }\end{array}$ & 2009 & $\begin{array}{l}\text { Geothermal } \\
\text { energy }\end{array}$ & $1.0 \times 2$ & $0.5-0.6$ & $\begin{array}{l}\text { Steam-liquid } \\
\text { mixture }\end{array}$ \\
\hline $\begin{array}{l}\text { Maoming, } \\
\text { China }\end{array}$ & 2009 & Waste heat & 0.36 & 0.41 & 418 \\
\hline Jinan, China & 2013 & Waste heat & 0.45 & 1.0 & 453 \\
\hline $\begin{array}{l}\text { Yongcheng, } \\
\text { China }\end{array}$ & 2011 & Waste heat & $0.83 \times 3$ & 0.7 & 440 \\
\hline $\begin{array}{l}\text { Shanghai, } \\
\text { China }\end{array}$ & 2009 & Waste heat & 0.5 & 0.78 & 447 \\
\hline Xinyu, China & 2009 & Waste heat & 0.8 & $0.4-0.5$ & $\begin{array}{l}\text { Steam-liquid } \\
\text { mixture }\end{array}$ \\
\hline $\begin{array}{l}\text { Shanghai, } \\
\text { China }\end{array}$ & 2012 & Waste heat & 0.22 & 1.3 & 473 \\
\hline $\begin{array}{l}\text { Xingtai, } \\
\text { China }\end{array}$ & 2011 & Waste heat & 1.1 & 1.8 & $\begin{array}{l}\text { Steam-liquid } \\
\text { mixture }\end{array}$ \\
\hline Minas & 2010 & Waste heat & 0.42 & 1.1 & 457 \\
\hline Gerais, Brazil & & & & & \\
\hline Milan, Italy & 2014 & Waste heat & 0.11 & \multicolumn{2}{|c|}{ series: HP145/HP204 } \\
\hline Ship, Sweden & 2014 & Waste heat & $0.1-1.6$ & \multicolumn{2}{|c|}{ series: Opcon Powerbox WST } \\
\hline
\end{tabular}


Table 2. Comparison of SRC and ORC power efficiencies under different conditions, unit: \%

\begin{tabular}{|c|c|c|c|c|c|c|}
\hline & $\begin{array}{l}\text { Evaporation } \\
\text { temperature }\end{array}$ & $373 \mathrm{~K}$ & $423 \mathrm{~K}$ & $473 \mathrm{~K}$ & $523 \mathrm{~K}$ & $573 \mathrm{~K}$ \\
\hline \multirow{9}{*}{$\begin{array}{l}\text { Working } \\
\text { fluid }\end{array}$} & Water & 10.92 & 17.02 & 21.39 & 24.51 & 26.58 \\
\hline & R123 & 9.59 & 13.62 & - & - - & - \\
\hline & Ammonia & 9.52 & - & - & - & - \\
\hline & Cis-butene & 9.49 & 13.03 & - & - - & - - \\
\hline & Hexane & 9.50 & 13.49 & 15.63 & - & - - \\
\hline & Ethanol & 10.48 & 15.75 & 18.90 & - & - - \\
\hline & R113 & 9.60 & 13.78 & 16.00 & - & - \\
\hline & Decane & 9.52 & 13.55 & 15.77 & 16.96 & 17.55 \\
\hline & Toluene & 10.22 & 15.25 & 18.46 & 20.49 & 21.67 \\
\hline
\end{tabular}

Note: The efficiencies of the expander, pump and generator are 0.75, 0.8 and 0.95, respectively. The condensation temperature is $313 \mathrm{~K}$. 
Table 3. Exergy losses in each individual component

\begin{tabular}{cc}
\hline Component & Exergy losses \\
PTC & $I_{P T C}=\left(s_{1}-s_{4}\right) m_{\mathrm{I}} T_{0}$ \\
SE & $I_{S E}=\left(s_{2}-s_{1}\right) m_{\mathrm{II}} T_{0}$ \\
HX1 & $I_{H X 1}=\left[\left(s_{3}-s_{2}\right) m_{\mathrm{I}}+\left(s_{5}-s_{8}\right) m_{\mathrm{II}}\right] T_{0}$ \\
P1 & $I_{P 1}=\left(s_{4}-s_{3}\right) m_{\mathrm{I}} T_{0}$ \\
Turbine & $I_{T U}=\left(s_{6}-s_{5}\right) m_{\mathrm{II}} T_{0}$ \\
HX2 & {$\left[\begin{array}{l}I_{H X 2}= \\
\text { P2 }\end{array}\right.$} \\
& $\left.I_{P 2}=\left(s_{7}-s_{6}\right)-\frac{h_{7}-h_{6}}{T_{0}}\right] s_{0} m_{\mathrm{II}}$
\end{tabular}


Table 4. Thermodynamic and environmental data of the working fluids

\begin{tabular}{|c|c|c|c|c|c|c|}
\hline Working fluid & $\begin{array}{l}\text { Normal } \\
\text { boiling } \\
\text { point }(\mathrm{K})\end{array}$ & $\begin{array}{c}\text { Critical } \\
\text { temperature } \\
(\mathrm{K})\end{array}$ & $\begin{array}{l}\text { Critical } \\
\text { pressure } \\
(\mathrm{MPa})\end{array}$ & $\begin{array}{l}\text { Safety } \\
\text { level }\end{array}$ & ODP & GWP \\
\hline Benzene & 353.23 & 562.05 & 4.89 & B2 & - - & - \\
\hline Cyclohexane & 353.89 & 553.64 & 4.08 & $\mathrm{~A} 2$ & 0 & very low \\
\hline $\mathrm{R} 141 \mathrm{~b}$ & 305.20 & 477.50 & 4.21 & A2 & 0.11 & 630 \\
\hline $\mathrm{R} 123$ & 300.97 & 456.83 & 3.66 & A1 & 0.012 & 120 \\
\hline Pentane & 309.21 & 469.70 & 3.37 & $\mathrm{~A} 2$ & 0 & very low \\
\hline $\mathrm{R} 365 \mathrm{mfc}$ & 313.30 & 460.00 & 3.27 & - - & 0 & 840 \\
\hline $\mathrm{R} 245 \mathrm{fa}$ & 288.29 & 427.16 & 3.65 & A1 & 0 & 820 \\
\hline Butane & 272.66 & 425.13 & 3.80 & B3 & - - & - \\
\hline Isobutene & 266.15 & 418.09 & 4.01 & B3 & - - & - - \\
\hline R236ea & 279.34 & 412.44 & 3.50 & - - & 0 & 710 \\
\hline
\end{tabular}

Table 5. Fixed parameters for calculation

\begin{tabular}{ll}
\hline Term & Value \\
\hline Pinch-point temperature difference & $5 \mathrm{~K}$ \\
Pump efficiency, $\varepsilon_{p}$ & 0.8 \\
Screw expander isentropic efficiency, $\varepsilon_{S E}$ & 0.75 \\
Turbine isentropic efficiency, $\varepsilon_{T}$ & 0.75 \\
Generator efficiency, $\varepsilon_{g}$ & 0.95 \\
Beam solar radiation, $G_{b}$ & $800 \mathrm{~W} / \mathrm{m}^{2}$ \\
Surface temperature of the sun, $T_{S}$ & $5800 \mathrm{~K}$ \\
\hline
\end{tabular}


Table 6. Theoretical optimum ORC evaporation temperature and the corresponding solar thermal power efficiency

\begin{tabular}{|c|c|c|c|c|}
\hline \multirow{2}{*}{$\begin{array}{l}\text { Working } \\
\text { fluid }\end{array}$} & \multicolumn{4}{|c|}{$\mathrm{T}_{5, \mathrm{P}} / \eta_{T, P}$} \\
\hline & $\begin{array}{l}\mathrm{T}_{\mathrm{H}}=473 \mathrm{~K} \\
\mathrm{~T}_{\mathrm{L}}=313 \mathrm{~K}\end{array}$ & $\begin{array}{l}\mathrm{T}_{\mathrm{H}}=473 \mathrm{~K} \\
\mathrm{~T}_{\mathrm{L}}=293 \mathrm{~K}\end{array}$ & $\begin{array}{l}\mathrm{T}_{\mathrm{H}}=523 \mathrm{~K} \\
\mathrm{~T}_{\mathrm{L}}=313 \mathrm{~K}\end{array}$ & $\begin{array}{l}\mathrm{T}_{\mathrm{H}}=523 \mathrm{~K} \\
\mathrm{~T}_{\mathrm{L}}=293 \mathrm{~K}\end{array}$ \\
\hline benzene & $361 \mathrm{~K} / 14.61 \%$ & $345 \mathrm{~K} / 16.04 \%$ & $369 \mathrm{~K} / 15.93 \%$ & $354 \mathrm{~K} / 16.92 \%$ \\
\hline cyclohexane & $353 \mathrm{~K} / 14.53 \%$ & $341 \mathrm{~K} / 15.96 \%$ & $359 \mathrm{~K} / 15.82 \%$ & $347 \mathrm{~K} / 16.84 \%$ \\
\hline $\mathrm{R} 141 \mathrm{~b}$ & $352 \mathrm{~K} / 14.49 \%$ & $336 \mathrm{~K} / 15.91 \%$ & $358 \mathrm{~K} / 15.78 \%$ & $345 \mathrm{~K} / 16.78 \%$ \\
\hline R123 & $345 \mathrm{~K} / 14.43 \%$ & $330 \mathrm{~K} / 15.85 \%$ & $356 \mathrm{~K} / 15.71 \%$ & $336 \mathrm{~K} / 16.70 \%$ \\
\hline pentane & $344 \mathrm{~K} / 14.39 \%$ & $330 \mathrm{~K} / 15.81 \%$ & $351 \mathrm{~K} / 15.66 \%$ & $336 \mathrm{~K} / 16.66 \%$ \\
\hline $\mathrm{R} 365 \mathrm{mfc}$ & $342 \mathrm{~K} / 14.35 \%$ & $327 \mathrm{~K} / 15.77 \%$ & $348 \mathrm{~K} / 15.62 \%$ & $332 \mathrm{~K} / 16.62 \%$ \\
\hline R245fa & $342 \mathrm{~K} / 14.35 \%$ & $327 \mathrm{~K} / 15.77 \%$ & $346 \mathrm{~K} / 15.61 \%$ & $331 \mathrm{~K} / 16.62 \%$ \\
\hline butane & $342 \mathrm{~K} / 14.34 \%$ & $327 \mathrm{~K} / 15.76 \%$ & $348 \mathrm{~K} / 15.60 \%$ & $331 \mathrm{~K} / 16.61 \%$ \\
\hline isobutene & $339 \mathrm{~K} / 14.33 \%$ & $327 \mathrm{~K} / 15.76 \%$ & $346 \mathrm{~K} / 15.60 \%$ & $331 \mathrm{~K} / 16.61 \%$ \\
\hline R236ea & $336 \mathrm{~K} / 14.28 \%$ & $323 \mathrm{~K} / 15.70 \%$ & $343 \mathrm{~K} / 15.54 \%$ & $327 \mathrm{~K} / 16.54 \%$ \\
\hline
\end{tabular}


Table 7. Parameters distribution and exergy losses of the SORC system for producing $100 \mathrm{~kW}$ electricity

\begin{tabular}{|c|c|c|c|c|}
\hline $\mathrm{T}_{\mathrm{H}} / \mathrm{T}_{\mathrm{L}}(\mathrm{K})$ & $473 / 313$ & $473 / 293$ & $523 / 313$ & $523 / 293$ \\
\hline $\mathrm{T}_{\mathrm{a}}(\mathrm{K})$ & 303 & 283 & 303 & 283 \\
\hline $\mathrm{T}_{1}(\mathrm{~K}) / \mathrm{P}_{1}(\mathrm{MPa})$ & $473 / 1.55$ & $473 / 1.55$ & $523 / 3.98$ & $523 / 3.98$ \\
\hline $\mathrm{T}_{2}(\mathrm{~K}) / \mathrm{P}_{2}(\mathrm{MPa})$ & $373 / 0.10$ & $373 / 0.10$ & $402 / 0.26$ & $402 / 0.26$ \\
\hline $\mathrm{T}_{3}(\mathrm{~K}) / \mathrm{P}_{3}(\mathrm{MPa})$ & $373 / 0.10$ & $373 / 0.10$ & $402 / 0.26$ & $402 / 0.26$ \\
\hline $\mathrm{T}_{4}(\mathrm{~K}) / \mathrm{P}_{4}(\mathrm{MPa})$ & $373 / 1.55$ & $373 / 1.55$ & $403 / 3.98$ & $403 / 3.98$ \\
\hline $\mathrm{T}_{5}(\mathrm{~K}) / \mathrm{P}_{5}(\mathrm{MPa})$ & $368 / 1.53$ & $368 / 1.53$ & $397 / 0.32$ & $397 / 0.32$ \\
\hline $\mathrm{T}_{6}(\mathrm{~K}) / \mathrm{P}_{6}(\mathrm{MPa})$ & $335 / 0.02$ & $321 / 0.01$ & $350 / 0.02$ & $336 / 0.01$ \\
\hline $\mathrm{T}_{7}(\mathrm{~K}) / \mathrm{P}_{7}(\mathrm{MPa})$ & $313 / 0.02$ & $293 / 0.01$ & $313 / 0.02$ & $293 / 0.01$ \\
\hline $\mathrm{T}_{8}(\mathrm{~K}) / \mathrm{P}_{8}(\mathrm{MPa})$ & $313 / 0.15$ & $293 / 0.15$ & $313 / 0.32$ & $293 / 0.32$ \\
\hline $\begin{array}{l}\text { Exergy loss in PTC } \\
(\mathrm{kW})\end{array}$ & 312.43 & 261.92 & 245.98 & 211.47 \\
\hline Exergy loss in SE (kW) & 24.51 & 20.22 & 20.99 & 17.79 \\
\hline $\begin{array}{l}\text { Exergy loss in HX1 } \\
(\mathrm{kW})\end{array}$ & 11.60 & 13.70 & 15.22 & 17.02 \\
\hline Exergy loss in P1 (kW) & 0.06 & 0.05 & 0.14 & 0.12 \\
\hline $\begin{array}{l}\text { Exergy loss in turbine } \\
\qquad(\mathrm{kW})\end{array}$ & 12.78 & 16.78 & 15.47 & 18.59 \\
\hline $\begin{array}{c}\text { Exergy loss in HX2 } \\
(\mathrm{kW})\end{array}$ & 13.25 & 12.37 & 12.21 & 11.79 \\
\hline Exergy loss in P2 (kW) & 0.04 & 0.03 & 0.07 & 0.06 \\
\hline $\begin{array}{c}\text { Total exergy losses } \\
\qquad(\mathrm{kW})\end{array}$ & 379.72 & 325.08 & 313.61 & 276.83 \\
\hline$\eta_{e x}(\%)$ & 19.24 & 20.59 & 20.74 & 21.40 \\
\hline$\eta_{T}(\%)$ & 13.68 & 15.03 & 14.74 & 15.62 \\
\hline
\end{tabular}




\section{Nomenclature}

\begin{tabular}{|c|c|c|c|}
\hline$A$ & aperture area, $m^{2}$ & SRC & steam Rankine cycle \\
\hline$C$ & heat capacity, $\mathrm{kJ} / \mathrm{kg} \cdot \mathrm{K}$ & $\mathrm{V}$ & valve \\
\hline E & exergy, $k W$ & VR & volume ratio \\
\hline$G$ & solar radiation, $W / m^{2}$ & & \\
\hline$h$ & enthalpy, $k J / k g$ & Subscripts & \\
\hline$m$ & mass flow rate, $\mathrm{kg} / \mathrm{s}$ & I , II & Cycle I , II \\
\hline$P$ & pressure, $M P a$ & $1-8$ & state points \\
\hline$T$ & temperature, $K$ & 0 & reference state \\
\hline$v$ & specific volume, $\mathrm{m}^{3} / \mathrm{kg}$ & $a$ & ambient \\
\hline$W$ & power output, $k W$ & $b$ & binary phase/ beam \\
\hline$\varepsilon$ & mechanic efficiency & $c$ & characteristic \\
\hline$\eta$ & system efficiency & cas & cascade \\
\hline & & $e x$ & exergetic \\
\hline Abbreviation & & $g$ & generator \\
\hline DSG & direct steam generation & in & inlet \\
\hline $\mathrm{HX}$ & heat exchanger & $l$ & liquid phase \\
\hline ORC & organic Rankine cycle & net & net \\
\hline $\mathrm{P}$ & Pump & op & optimum \\
\hline PCM & phase-change material & out & outlet \\
\hline PR & pressure ratio & $p$ & $\begin{array}{l}\text { peak point/ pressure/ } \\
\text { pump }\end{array}$ \\
\hline
\end{tabular}


PTC

SE

SEGS

SORC parabolic trough collectors

screw expander

solar electricity generation system steam-organic Rankine cycle
$\boldsymbol{S} \quad$ solar/ isentropic

single single stage

$T$ thermal/ turbine 